\title{
Analysis of synonymous codon usage patterns in sixty-four different bivalve species
}

Marco Gerdol, Gianluca De Moro, Paola Venier, Alberto Pallavicini

Synonymous codon usage bias (CUB) is a defined as the non-random usage of codons encoding the same amino acid across different genomes. This phenomenon is common to all organisms and the real weight of the many factors involved in its shaping still remains to be fully determined. So far relatively little attention has been put in the analysis of CUB in bivalve mollusks due to the limited genomic data available. Taking advantage of the massive sequence data generated from next generation sequencing projects, we explored codon preferences in 64 different species pertaining to the six major evolutionary lineages in Bivalvia. We detected remarkable differences across species, which are only partially dependent on phylogeny. While the intensity of CUB is mild in most organisms, a heterogeneous group of species (including Arcida and Mytilida, among the others) display higher bias and a strong preference for AT-ending codons. We show that the relative strength and direction of mutational bias, selection for translational efficiency and for translational accuracy contribute to the establishment of synonymous codon usage in bivalves. Although many aspects underlying bivalve CUB still remain obscure, we provide for the first time an overview of this phenomenon in this large, commercially and environmentally important, class of marine invertebrates. 
1 Marco Gerdol ${ }^{1}$, Gianluca De Moro ${ }^{1}$, Paola Venier ${ }^{2}$, Alberto Pallavicini1 ${ }^{*}$

2

$3 \quad{ }^{1}$ Department of Life Sciences, University of Trieste, Via Giorgieri 5, 34127 Trieste (TS), Italy

4 2Department of Biology, University of Padova, Via U.Bassi 58/ B, 35121 Padova (PD), Italy

5

6 *Corresponding author: Alberto Pallavicini, pallavic@units.it, Department of Life Sciences,

7 University of Trieste, Via Giorgieri 5, 34127 Trieste (TS), Italy

8

9 Authors e-mail addresses

10 Marco Gerdol: mgerdol@units.it

11 Gianluca De Moro: gdemoro@units.it

12 Paola Venier: paola.venier@unipd.it

13 Alberto Pallavicini: pallavic@units.it 


\section{Abbreviations}

15 CAI: Codon Adaptation Index

16 CDS: coding sequence

17 CUB: Codon Usage Bias

18 ENC: Effective Number of Codons

$19 \mathrm{GC}_{3}$ : GC content at the third codon base

20 NGS: Next Generation Sequencing

21 ORF: Open Reading Frame

22 RNA-seq: RNA-sequencing

23 RSCU: Relative Synonymous Codon Usage 


\section{Introduction}

Codon usage bias (CUB), intended as the non-random usage of synonymous codons in the protein translation process, can be observed in virtually all organisms. This phenomenon widely varies across different species and it is expected to significantly influence molecular genome evolution (Hershberg \& Petrov, 2008; Sharp, Emery \& Zeng, 2010; Plotkin \& Kudla, 2011).

The mechanisms behind CUB are complex and not completely understood, since a large number of different intertwined biological factors are correlated with the choice of optimal codons. These include the GC content, both at gene and at whole genome level (Sueoka \& Kawanishi, 2000; Zeeberg, 2002; Wan et al., 2004; Palidwor, Perkins \& Xia, 2010), gene length, structure, expression levels and transcriptional efficiency (Gouy \& Gautier, 1982; Sharp, Tuohy \& Mosurski, 1986; Bains, 1987; Eyre-Walker, 1996; Duret \& Mouchiroud, 1999), protein structure and amino acid composition (D'Onofrio et al., 1991; Xie et al., 1998), tRNA abundance (Ikemura, 1985), selection, mutational bias and random drift (Bulmer, 1991; Sharp et al., 1993; Kliman \& Hey, 1994).

While CUB has been extensively studied in many viruses, prokaryotes, as well as in a number of eukaryote model species (Stenico, Lloyd \& Sharp, 1994; Powell \& Moriyama, 1997; Ermolaeva, 2001; Jenkins \& Holmes, 2003; Gu et al., 2004; Mitreva et al., 2006; Vicario, Moriyama \& Powell, 2007; Behura \& Severson, 2012), so far little attention has been focused on non-model invertebrates. In particular, the large phylum of Mollusca has been almost completely neglected, even though it comprises more than 9,000 species including some of a great relevance as sea food and as sentinel organisms for coastal water biomonitoring (Gosling, 2003).

For a long time, genomic studies in Bivalvia have been limited by the lack of sequence data. However, the recent advances in the field of high throughput sequencing permitted to unravel the 
47 genomes of Crassostrea gigas and Pinctada fucata (Takeuchi et al., 2012; Zhang et al., 2012)

48 and to obtain of a massive amount of transcriptomic data, useful for large-scale comparative

49 studies (Suárez-Ulloa et al., 2013).

50 The only study performed so far on codon usage in Bivalvia was based on ESTs generated by

51 Sanger sequencing and targeted a single species, the Pacific oyster C. gigas (Sauvage et al., 52 2007). Here, we provide the first comprehensive study of CUB in bivalves: based on the analysis 53 of 2,846 evolutionarily conserved protein-coding genes in 64 different species, we calculated 54 codon frequencies and Relative Synonymous Codon Usage (RSCU) values for each species, thus 55 identifying both preferred and avoided codons, and calculating the overall CUB at the species 56 transcriptome level.

57 Our data highlight significant differences among the analyzed species and clearly identify a 58 bivalve subgroup with an increased codon bias, comprising Mytilida, Arcida and several different species of the Imparidentia lineage. We discuss the evolution of CUB in Bivalvia in relation with the possible underlying factors such as species phylogeny, mutational bias and natural selection. Overall, the results of these analysis bring new insights on the evolution of bivalve genomes and on the major forces driving the evolution of codon usage in bivalves and will provide a reference for improving the annotation of protein-coding genes in future bivalve genome sequencing efforts.

\subsection{Data sources}


69 We considered two bivalve mollusk species with a fully sequenced genome $(C$. gigas and $P$.

70 fucata) (Takeuchi et al., 2012; Zhang et al., 2012) and 62 other species whose transcriptome has

71 been sequenced using next generation sequencing technologies and deposited in public sequence

72 databases. When both 454 Life Sciences and Illumina-generated sequencing reads were available

73 for a same species, the latter were chosen due to higher throughput and lower rate of sequencing

74 errors. Namely, Illumina reads were used for species Anadara trapezia, Arctica islandica,

75 Argopecten irradians, Astarte sulcata, Atrina rigida, Azumapecten farreri, Bathymodiolus

76 platifrons, Cardites antiquata, Cerastoderma edule, Corbicula fluminea, Crassostrea angulata,

77 Crassostrea corteziensis, Crassostrea hongkongensis, Crassostrea virginica, Cycladicama

78 cumingii, Cyrenoida floridana, Diplodonta sp. VG-2014, Donacilla cornea, Elliptio complanata,

79 Ennucula tenuis, Eucrassatella cumingii, Galeomma turtoni, Glossus humanus, Hiatella arctica,

80 Lampsilis cardium, Lamychaena hians, Mactra chinensis, Margaritifera margaritifera,

81 Mercenaria campechiensis, Meretrix meretrix, Mizuhopecten yessoensis, Mya arenaria,

82 Myochama anomioides, Mytilus californianus, Mytilus edulis, Mytilus galloprovincialis, Mytilus

83 trossulus, Neotrigonia margaritacea, Ostrea chilensis, Ostrea edulis, Ostrea lurida, Ostreola

84 stentina, Pecten maximus, Perna viridis, Pinctada martensii, Placopecten magellanicus,

85 Polymesoda caroliniana, Pyganodon grandis, Ruditapes decussatus, Ruditapes philippinarum,

86 Sinonovacula constricta, Solemya velum, Sphaerium nucleus, Uniomerus tetralasmus and Villosa

87 lienosa (Qin et al., 2012; Ghiselli et al., 2012; Chen et al., 2013; Meng et al., 2013; Gerdol et al.,

88 2014; Fu et al., 2014; Zhang et al., 2014; Pauletto et al., 2014; de Sousa et al., 2014; Zhao et al.,

89 2014; Cornman et al., 2014; Zapata et al., 2014; Prentis \& Pavasovic, 2014; González et al.,

90 2015). 454 Life Sciences sequences were used for Bathymodiolus azoricus, Geukensia demissa,

91 Laternula elliptica, Mimachlamys nobilis, Pinctada maxima, Saccostrea glomerata, and 
92 Tegillarca granosa (Clark et al., 2010; Philipp et al., 2012; Egas et al., 2012; Jones et al., 2013;

93 Fields et al., 2014). Details about the data used for the different species are provided in Table 94 S1.

95 Sequence data were processed as follows: predicted CDS from the fully sequenced genomes of 96 C. gigas (release 9) and P. fucata were retrieved from http://oysterdb.cn and 97 http://marinegenomics.oist.jp/pinctada fucata, respectively. De novo transcriptome assemblies were performed for all the other 62 bivalve species with the CLC Genomics Workbench (v.7.5, CLC Bio, Aarhus, Denmark) using the de novo assembly tool with "automatic word size" and "automatic bubble size" parameters selected, and setting the minimum allowed contig length to $300 \mathrm{bp}$.

102 In all transcriptomes, ORFs (Open Reading Frames) longer than 100 codons were predicted with 103 TransDecoder (http://transdecoder.sourceforge.net). We selected the predicted CDS of C. gigas, 104 and of one representative species for the Imparidentia (R. decussatus), Protobranchia (S. velum) 105 and Palaeoheterodonta ( $P$. grandis) lineage to identify a subset of evolutionarily conserved protein-coding genes with a 1:1 orthology ratio across Bivalvia. This was achieved by 107 performing reciprocal tBLASTx searches (the e-value threshold was set a $1 \times 10^{-10}$ and only hits displaying sequence identity $>50 \%$ were considered). This procedure resulted in a selection of 2,846 conserved protein-coding genes, whose orthologous sequences were retrieved in the remaining 60 species. Due to the heterogeneous tissue and developmental stage origin, the

111 different sequencing platforms and depth applied, several of these evolutionarily sequences could 112 not be identified or were fragmented in some transcriptomes. In order to ensure a minimum 113 quality criteria, all the selected species had to display at least $25 \%$ of the sequences included in 114 the dataset of evolutionarily conserved genes, with an average length $>500$ nucleotides. A 
115 number of additional transcriptomes derived from publicly available data did not meet such

116 criteria and were therefore not included in our analyses (Table S2).

\subsection{Codon frequencies and codon usage statistics}

119 The sets of evolutionarily conserved genes retrieved for each species were individually processed 120 with the cusp tool of the EMBOSS package (Rice, Longden \& Bleasby, 2000) obtaining codon 121 frequencies and GC composition for each codon position. RSCU values for each individual 122 codon were calculated for each species as described by Sharp and colleagues (Sharp, Tuohy \&

123 Mosurski, 1986). The effective number of codons (ENC) for each species was calculated 124 according to Wright (1990) using the EMBOSS chips tool, summing codons over al sequences 125 (Rice, Longden \& Bleasby, 2000). The sENC-X values were determined for every amino acid 126 for each species and scaled to a range of values between 0 and 1 according to Moriyama and 127 Powell (1997). EMBOSS chips was also used to calculate ENC for individual genes whenever 128 necessary. We identified a reference set of 50 highly expressed genes for the calculation of 129 Codon Adaptation Index (CAI) based on the average expression in $C$. gigas digestive gland 130 (SRA: SRX093412), gills (SRA: SRX093414) and hemocytes (SRA: SRX093417) RNA-seq 131 libraries and their inclusion in the above mentioned set of 2,846 genes conserved across bivalves. 132 Gene expression was calculated as TPM (Transcripts Per Million) (Wagner, Kin \& Lynch, 133 2012), with the RNA-seq mapping tool included in the CLC Genomics Workbench 8.5 (Aarhus, 134 Denmark), setting length and similarity fraction parameters to 0.75 and 0.98 and 135 insertion/deletion/mismatch penalties to 3. Orthologous genes were used for CAI calculation in 136 other species. CAI values were computed with CAI calculator 2 (Wu, Culley \& Zhang, 2005).

137 The gene expression levels of M. galloprovincialis transcripts were calculated using the digestive 
138 gland (SRA: SRX126945-8), gills (SRA: SRX389466) and hemocytes (SRA: SRX389338)

139 RNA-seq libraries (Gerdol et al., 2014; Moreira et al., 2015).

140 Scatter plots were generated between ENC and the average GC content calculated at the third 141 codon position $\left(\mathrm{GC}_{3}\right)$ for each species, between ENC and $\mathrm{sENCx}$ and between ENC and CAI;

142 Paerson correlation coefficients and linear regression analyses were computed with $\mathrm{R}$ 3.1.0

143 (http://www.r-project.org).

\subsection{Hierarchical clustering analysis}

146 The Relative Synonymous Codon Usage (RSCU) values calculated for the 59 informative 147 codons in each species were used to build a tabular file. STOP, ATG (encoding Met) and TGG 148 (encoding Trp) codons were excluded from this analysis. This file was used as an input for

149 Cluster 3 (de Hoon et al., 2004), thus generating a species distance matrix. Hierarchical 150 clustering was performed by using the Euclidean distance as a similarity metric and complete 151 linkage as a clustering method. 
152

153

154

155

156

157

158

159

160

161

162

163

164

165

166

167

168

169

170

171 172

173

174

\section{Results and discussion}

\subsection{CUB varies across bivalve species}

The codon frequencies and RSCU values calculated for the 64 bivalve species analyzed are displayed in Tables $\mathbf{S 3}$ and S4. As shown in the comparative overview of Fig. 1, RSCU values are usually very similar in closely related species, such as in the case of Mytilida, Ostreoidea and Unionida (panels A, B and C), but marked differences can be observed in an higher-order comparison (panel D).

Different species clearly show a different tendency to the preferential usage of specific codons, as exemplified by the average Effective Number of Codons (ENC) (Wright, 1990) values in Table 1. Overall, the observed ENC values range between 40.65 (in the Chinese surf clam $M$. chinensis) and 56.80 (G. turtoni) across the analyzed species, while the theoretical value is comprised between 21 (if only a single codon is used for each amino acid) and 61 (if all codons are used with equal frequency). Most bivalve species display a weak CUB, using on average over 50 out of the 61 available codons, and only a limited number of bivalve species display an ENC value comparable to that of other invertebrates (the ENC range is 45-48 in Drosophila and nematodes) (Powell \& Moriyama, 1997; Mitreva et al., 2006; Vicario, Moriyama \& Powell, 2007).

3.2. Species clustering based on CUB does not reflect the evolutionary history of

\section{Bivalvia}

We computed RSCU values for the 59 informative codons of each species to perform a hierarchical clustering of species with Cluster 3, thereby investigating the role of CUB in the 
175 evolution of bivalve genomes. The resulting dendrogram is shown in Fig. 2. Although phylogeny

176 and CUB-based clustering are in agreement, in several cases, up to the order level, the six major

177 lineages of Anomalodesmata, Archiheterodonta, Imparidentia, Palaeoheterodonta, Protobranchia

178 and Pteriomorphia expected from molecular phylogeny (Bieler et al., 2014) are hardly

179 distinguishable. This observation is consistent with data previously reported for nematodes by

180 Mitreva and colleagues (Mitreva et al., 2006), who reported a connection between codon

181 distribution and phylogeny only for closely related species, up to the genus level. In bivalves

182 such a relationship seems to extend a bit further, in some cases up to one of the six major

183 evolutionary lineages, as for instance in Palaeoheterodontha, which include the freshwater

184 mussels of the order Unionida and the saltwater cams of the order Trigoniida, or

185 Archiheterodonta, which only comprise four relatively small extant families. While in some

186 cases (e.g. Mytilida and Ostreoidea) all the species maintain a similar usage of synonymous

187 codons (Fig. 1), in others (e.g. Venerida) remarkable differences among species are clearly 188 visible.

189 In essence, the clustering based on codon usage divides the bivalve species into two largely 190 divergent groups:

191 (I) The first group is very heterogeneous, comprising 43 species with ENC $>52$ (with the exception of L. hians). Two subgroups are detectable: group I-a comprises all the Pectinida and Ostreoidea species (Pteriomorphia), two Anomalodesmata ( $M$. anomiodes and L. elliptica), two Protobranchia (E. tenuis and S. velum) and the Imparidentia G. turtoni, M. arenaria and $S$. constricta. The species pertaining to this subgroup show a weak CUB, with ENC 54-58 and $\mathrm{GC}_{3}$ very close to $50 \%$ (averaging $\sim 49 \%$ ). 

spp. (Pteriomorphia, Pterioidea), eight unrelated Imparidentia and the three Archiheterodonta species. Compared to subgroup I-a, the observed CUB is slightly higher, including species with $\mathrm{ENC}$ ranging from $\sim 52$ to $\sim 54$, but $\mathrm{GC}_{3}$ is remarkably lower than group Ia, averaging $\sim 43 \%$.

(II) The second major group comprises the remaining 20 species, including the 204 Pteriomorphia groups Mytilida, Arcida and Pinnoidea (represented by the lone species $A$. rigida), together with various Imparidentia species classified as Cardioidea, Cyamiidae, Mactroidea, Sphaeriidae and Venerida, implying that this well-defined group of bivalves with high CUB (ENC 40-52) and low $\mathrm{GC}_{3}(30-40 \%$, with the outlier $M$. chinensis reaching $23 \%$ ) comprises phylogenetically distant species.

\subsection{Codon usage is biased towards $\mathbf{A} / \mathbf{T}$ ending codons in Bivalvia}

212 Here we report the most commonly used codon(s) for each amino acid, designing as "preferred 213 codons" all the codons used more frequently than expected (RSCU $>1$ ), and we investigate the 214 correlation between their frequency and overall codon usage bias (negative ENC) across the 215 bivalve species analyzed (Vicario, Moriyama \& Powell, 2007).

216 Figure 3, panel A summarizes the number of bivalve species where a given codon is preferred, 217 evidencing that, despite the difference in overall ENC values, several preferred and avoided 218 codons are shared by most, if not by all, bivalves: this is the case, for example, of ACA (Thr), AGA and AGT (Arg), TCA (Ser), TGT (Cys), CCA (Pro), GCT (Ala) and GGA (Gly). On the 220 other hand, the RSCU values of ACG (Thr), AGC (Ser), TCG and CTA (Leu), TGC (Cys), CCG 
221 (Pro), CGC and CGG (Arg), GCG (Val) and GGG (Gly) are always lower than 1, indicating that 222 these codons are avoided in all species. In general, A/T-ending codons appear to be preferred

223

224

225

226

over those ending in $\mathrm{G} / \mathrm{T}$, but some notable exceptions exist, including the two $\mathrm{C}$-starting codons encoding the six-fold degenerate amino acids Ser and Arg. While G-ending codons are not uncommon, C-ending codons are almost invariably avoided.

However, when the correlation between codon frequencies and overall CUB of bivalve species is taken into account, the important weight of $\mathrm{A} / \mathrm{T}$ ending codons on bivalve codon bias becomes evident, (Fig. 3, panel B). Indeed, the high CUB of all the species pertaining to clustering group II (Fig. 2) appears to be mostly resulting from an increased use of A/T-ending codons over those ending in $\mathrm{G} / \mathrm{C}$, also explaining the significant negative correlation between $\mathrm{ENC}$ and $\mathrm{GC}_{3}$ across species (see Section 3.4 below). This correlation is significant for most codons with, once again, the exception of the C-starting codons encoding the six-fold degenerate amino acids Leu and Arg. On the contrary, the frequency of $\mathrm{G} / \mathrm{C}$ ending codons is significantly and negatively correlated with CUB in all cases, with the exception of TTG (Leu).

We explored in detail the contribution of different amino acids to CUB in bivalves by calculating s-ENCx values for each amino acid and correlating this parameter to the overall CUB of each species. This measure is a variation of ENC (Wright, 1990) which is scaled in a range from 0-1 for each amino acid independently from the level of redundancy, and which can be used to estimate the relative intensity of CUB across the 18 degenerate amino acids (Moriyama \& Powell, 1997). As reported in Table S5 and Fig. 4, the sENC-x values of all amino acids negatively correlate with ENC with significant p-values, including those with relatively low average s-ENCx values. The only exception is represented by of Gln, which is likely related to the fact that it is the only two-fold degenerate amino acid to display a strong preference for a 
244 G/C-ending (CAG) over an A/T-ending codon (CAA) (see Fig. 3, panel A). Overall, Arg is

245 certainly the amino acid which accounts for the greatest CUB in bivalves, as highlighted by the

246 high average s-ENCx value (0.32), followed by Pro, Thr, Cys, Ala, Gly, Ser and Leu, all

247 characterized by values $>0.1$.

248

\section{4. $\quad$ Effects of mutational bias and selection on CUB in Bivalvia}

250

251

252

253

254

255

256

257

258

259

260

261

262

263

264

265

266

Although the knowledge of the factors underlying the preferential use of certain codons has remarkably increased over the past few decades, the real contribution of the several potentially contrasting forces involved in shaping CUB still remains a matter of debate in the scientific community.

Mutational bias, intended as the non-randomness of mutational patterns, certainly has a major role in determining codon usage in prokariotes, as well as in many eukaryotes (Muto \& Osawa, 1987; Sémon, Lobry \& Duret, 2006). A critical parameter tightly linked to mutational bias is genomic GC content, which in turn strongly influences the coding CG content (Knight, Freeland \& Landweber, 2001) and $\mathrm{GC}_{3}$ (Mitreva et al., 2006). Actually, all amino acids, with the exception of the non-degenerate methionine and tryptophan, tolerate $\mathrm{A} / \mathrm{T}$ to $\mathrm{C} / \mathrm{G}$ changes in the third codon position and thus, in organisms where mutational bias is dominant over other factors, the occurrence of $\mathrm{G} / \mathrm{C}$-ending codons should follow the total genomic GC content. However, even in such cases some deviations are observed, in particular for the 6-fold degenerated Arg and Leu, which also tolerate synonymous mutations at the first codon position (Palidwor, Perkins \& Xia, 2010).

In bivalves, average $\mathrm{GC}_{3}$ appears to be tightly related to $\mathrm{ENC}$ (Fig. 5), as these two variables could be strongly correlated by linear regression with $\mathrm{R}^{2}=0.92\left(\mathrm{p}\right.$-value $\left.=2.86 \times 10^{-36}\right)$. Overall, 
267 while $\mathrm{GC}_{3}$ can assume values as low as $\sim 23$ in M. chinensis, $\mathrm{GC}_{3}$ and $\mathrm{AT}_{3}$ contents become even 268 in species displaying weak CUB (and high ENC). Based on these observations and the well269 documented correlation between genomic $\mathrm{GC}$ content and coding $\mathrm{GC}_{3}$, one could hypothesize 270 that the bivalves pertaining to the clustering group II possess a similar genomic GC content, 271 lower than all the bivalve species included in the heterogeneous clustering group I, thus 272 explaining their common placement in a well-distinct cluster regardless of the reported 273 phylogenetic distance (Fig. 2). On the contrary, the bivalve transcriptomes of the clustering 274 group Ia show a $\mathrm{GC}_{3}$ not far from 50\%, accompanied by $\mathrm{ENC}$ values higher than 54 (Fig. 5), which would suggest that the absence of a strong CUB is linked to a lack of mutational bias. However, the genomic data currently available for bivalves do not support this view, since the differences in genomic GC content among species are minimal. The fully sequenced genomes of P. fucata and C. gigas possess a relatively low $\mathrm{G} / \mathrm{C}$ composition $(33.69 \%$ and $32.33 \%$, respectively) (Takeuchi et al., 2012; Zhang et al., 2014) and partial data from $A$. farreri and $M$. galloprovincialis indicate a similar GC content for these two species $(35.75 \%$ and $31.65 \%$, respectively) (Zhao et al., 2012; Nguyen, Hayes \& Ingram, 2014). Therefore, while the A/T-rich nature of most bivalve genomes is consistent with a role of mutational bias towards the preferential choice of $\mathrm{A} / \mathrm{T}$-ending codons in bivalves (Section 3.3), other factors might be taken into account to explain the differences in CUB among these marine organisms.

Among these, selection for translational speed and accuracy are certainly among the most relevant, as they can potentially overcome and mask the effects of mutational bias on CUB. This is the case, for example, of Drosophila spp. and of Strongylocentrotus purpuratus, which preferentially use $\mathrm{G} / \mathrm{C}$ ending codons despite having $\mathrm{A} / \mathrm{T}$ rich genomes (Vicario, Moriyama \& Powell, 2007; Kober \& Pogson, 2013). The selection for translational speed is evident in many 
290 unicellular and multicellular organisms, where the preferential use of optimal codons by highly

291 expressed genes, with the aim to maximize the rate of elongation during protein synthesis

292 (Marais \& Duret, 2001), has been clearly demonstrated (Gouy \& Gautier, 1982; Powell \&

293 Moriyama, 1997; Duret, 2000). Nevertheless, the correlation between gene expression and CUB

294 is not universally applicable, as the selection for translational speed appears to be weak in some

295 species (Hiraoka et al., 2009).

296 Natural selection also potentially shapes codon usage to improve translational accuracy, reducing

297 the risk of missense errors during the translational process (Akashi, 1994; Eyre-Walker, 1996).

298 Even though this model of selection predicts a higher CUB in genes encoding longer proteins, a

299 positive correlation between CUB and protein length has only been observed in bacteria, while

300 on the opposite an unexpected negative correlation has been described in a number of

301 eukaryotes, including S. cerevisiae, D. melanogaster and C. elegans (Moriyama \& Powell, 1998;

302 Duret \& Mouchiroud, 1999). Even though differences in selective constraints between

303 prokaryotes and eukaryotes have been evoked to explain this contradiction, the relationship

304 between CUB and protein length still remains obscure (Marais \& Duret, 2001).

305 The investigation of these two selective forces in bivalves is complicated by the

306 incomplete/fragmented nature of de novo assembled transcriptomes and by the limited gene

307 expression resources available. We correlated CUB with gene expression (in three tissues:

308 digestive gland, gills and hemocytes) and with ORF (protein) length in C. gigas, the most

309 appropriate bivalve species for this purpose due to the completeness of its genome annotation

310 and availability of gene expression data. We observed a significant positive correlation between

311 CUB (negative ENC) and gene expression in the three tissues analyzed, as well as between CUB

312 and ORF (protein) length (Table 2), which would suggest that both selection for translational 
313 speed and accuracy are actively shaping codon usage in oyster. However, we also observed a

314 highly significant, negative correlation between $\mathrm{GC}_{3}$ and gene expression and between $\mathrm{GC}_{3}$ and

315 protein length, which seem to contradict the mutational bias given by the A/T-rich nature of the

316 oyster genome. This observation matches the results obtained in a previous work conducted with

317 limited expression data based on Sanger EST sequencing, which suggested that translational

318 selection acts as a contrasting force to mutational bias in oyster, effectively counteracting its

319 action in highly expressed genes (Sauvage et al., 2007). Our data further indicate that, besides

320 the selection for translational speed, also the selection for translational accuracy provides a

321 contribution to the selection of $\mathrm{G} / \mathrm{C}$-ending codons in oyster.

322 The contrasting action of mutational bias and selection becomes particularly evident while taking

323 into consideration the correlation between CAI, a directional measure of CUB which is based on

324 a reference set of highly expressed genes (Sharp \& Li, 1987), and ENC, which on the other hand

325 is a non-directional measure which does not permit to appreciate the contribution of opposite

326 forces (in this case mutational bias towards A/T-ending codons and selection towards G/C-

327 ending codons). Indeed, in oyster and in all the other species clusterized in group I (see Fig. 2),

328 the scatter in the correlation plot between CAI and ENC appears to be quite relevant (Fig. 6;

329 Paerson correlation coefficients are -0.44 for $C$. gigas and -0.38 for P. magellanicus). This

330 indicates that the mutational bias towards $\mathrm{A} / \mathrm{T}$ is counterbalanced by natural selection in favor of

$331 \mathrm{G} / \mathrm{C}$-ending in a relevant number of genes. However, the significant correlation between ENC

332 and GC3 at the whole protein-coding transcriptome level (Paerson correlation $=0.16$, $\mathrm{p}$-value $=$

$3335.42 \times 10^{-148}$ ) indicates that the weight of $\mathrm{A} / \mathrm{T}$ mutational bias is still dominating over that of $\mathrm{G} / \mathrm{C}$

334 selection in most oyster genes. 
335 Overall, it is likely that in all species pertaining to clustering group I, whose coding $\mathrm{GC}_{3}$ sensibly

336 deviates from the frequency expected by genomic GC content, the mutational bias towards A/T-

337 ending codons is countered by the opposite forces of selection for translational speed and

338 accuracy, leading to moderate/low CUB.

339 On the other hand, the correlation between CAI and ENC in the bivalve species pertaining to 340 clustering group II is highly significant (Fig. 6, Paerson correlation coefficients are -0.87 for $M$.

341 chinensis and -0.71 for $M$. californianus). To better interpret this result, we extended the analysis

342 performed in oyster to a representative species of this group, M. galloprovincialis, limiting our

343 calculations to full-length protein-coding transcripts (Table 2). Overall, like in oyster, the

344 significant positive correlation between gene expression and $\mathrm{GC}_{3}$ over three different tissues

345 indicates that selection for translational speed acts towards G/C-ending codons. However, unlike

346 oyster, this appears to have no effect on CUB on the whole transcriptome scale, as the correlation

347 between gene expression and ENC was not significant. In addition, we observed that, in contrast

348 with oyster, the selection for translational accuracy is biased towards A/T-ending codons (i.e.

$349 \mathrm{GC}_{3}$ and protein length are negatively correlated). Overall, the M. galloprovincialis average $\mathrm{GC}_{3}$

350 is $30.80 \%$, a value which is very close to the GC genomic content, further indicating that

351 mutational bias and selection for translational accuracy, which both act in favor of A/T-ending,

352 are largely dominating over the opposite selection for translational speed in mussel.

\section{Conclusion}

In this paper we presented a comprehensive and well supported overview of CUB in 64 different bivalve species, including both marine and freshwater species, based on the analysis of nearly 
358 CUB is systematically investigated in such a large and important class of invertebrates, the

359 largest one after Insecta. We show that bivalves can be divided into two distinct groups, based on

360 the intensity of the bias towards the use of optimal codons. While in many species CUB appears

361 to be relatively weak, Mytilida, Arcida and several Imparidentia species show a remarkable

362 preference for $\mathrm{A} / \mathrm{T}$-ending codons.

363 Given the poor correlation between CUB and bivalve taxonomy, other factors are expected to 364 drive the evolution of CUB towards the same direction in distantly related species. We 365 investigated this issue in C. gigas and M. galloprovincialis, two species displaying low and high 366 CUB, respectively. Our analyses pointed out that:

367 (i) Bivalves are subject to mutational bias towards $\mathrm{A} / \mathrm{T}$-ending codons, due to the low 368 GC content of their genomes. Although the nucleotide genome composition should be 369 other factors.

(ii) Gene expression is positively correlated with $\mathrm{GC}_{3}$, which indicates a selection towards $\mathrm{G} / \mathrm{C}$-ending codons, acting to maximize the rate of elongation of protein reflected by a low $\mathrm{GC}_{3}$, some species display an almost even nucleotide content at the third codon position, which could be explained by the contrasting action exerted by synthesis for highly expressed transcripts. The different intensity of this selective force, opposed to mutational bias, might partly explain differences in CUB among species with similar genomic GC content.

(iii) Although the selection for translational accuracy, evidenced by the correlation between protein length and CUB, is also active in bivalves, the direction of this selective force varies across species, either reinforcing (in M. galloprovincialis) or counteracting (in $C$. gigas) mutational bias. 
381 In conclusion, multiple factors contribute to CUB in bivalves, and the specific weight of each of

382 them is still difficult to be determined with certainty considering the limited genomic resources

383 available for most species. However, based on the data collected so far, the different intensity of

384 the opposing forces represented by mutational bias towards A/T-ending codons and by selection

385 for translational speed towards G/C-ending codons appear to be two major players in this

386 process. Further study will be certainly needed to ascertain whether this model can be extended

387 to all bivalve species once additional genomic resources will become available. Such analyses

388 could also benefit from the integration of additional data such as the abundance of isoaccepting

389 tRNAs and data concerning effective population size of each species.

390 This large scale analysis supports the progressive understanding of molecular genome evolution

391 in bivalves and it is potentially useful for many different applications. For example, as we have

392 previously explained, codon usage is known to widely vary across genes based on their

393 expression level. The calculation of CAI could be used to predict the expression level and the

394 transcriptional efficiency of unknown genes and to assess the adaptation of viral genes to their

395 bivalve hosts (Sharp \& Li, 1987). Codon bias also has profound implications on codon-based

396 phylogenetic reconstructions, which could be optimized to avoid the over-estimation of

397 divergence between distantly related species and the under-estimation of divergence between

398 closely related ones (Christianson, 2005).

399 But, above all, one of the key applications of codon usage in the post-genomic era is certainly the

400 annotation of newly sequenced genomes. As the raw genomic sequences of new organisms

401 become available, new tools are required to efficiently identify genes and to predict their

402 structure and boundaries, in particular in non-model invertebrate species, which show a very

403 high proportion of genes without similarity to sequences deposited in public databases. The 
404 oyster genome has already evidenced that homology-based annotation methods perform rather 405 poorly for certain gene families, highlighting the need for integrating additional parameters in 406 gene prediction algorithms to optimize annotation (Gerdol, Venier \& Pallavicini, 2014). A 407 number of algorithms which take into account species-specific CUB information have been 408 developed, trying to identify protein coding sequences based on their congruence with a 409 reference codon usage table (Gribskov, Devereux \& Burgess, 1984). This task is particularly 410 important and complicated in Bivalvia, since genomic analyses in this taxa are quickly 411 expanding and only two species present a completely sequenced and annotated genome (Suárez412 Ulloa et al., 2013). 


\section{References}

414 Akashi H. 1994. Synonymous codon usage in Drosophila melanogaster: natural selection and translational accuracy. Genetics 136:927-935.

Bains W. 1987. Codon distribution in vertebrate genes may be used to predict gene length. Journal of Molecular Biology 197:379-388.

Behura SK., Severson DW. 2012. Comparative analysis of Codon usage bias and Codon context patterns between dipteran and hymenopteran sequenced genomes. PLOS ONE 7.

Bieler R., Mikkelsen PM., Collins TM., Glover EA., González VL., Graf DL., Harper EM., Healy J., Kawauchi

Bulmer M. 1991. The selection-mutation-drift theory of synonymous codon usage. Genetics 129:897GY., Sharma PP., Staubach S., Strong EE., Taylor JD., Tëmkin I., Zardus JD., Clark S., Guzmán A., McIntyre E., Sharp P., Giribet G. 2014. Investigating the Bivalve Tree of Life - an exemplar-based approach combining molecular and novel morphological characters. Invertebrate Systematics

Chen H., Zha J., Liang X., Bu J., Wang M., Wang Z. 2013. Sequencing and de novo assembly of the Asian clam (Corbicula fluminea) transcriptome using the Illumina GAllx method. PloS One 8:e79516. Journal of Botany 92:1221-1233.

Clark MS., Thorne MA., Vieira FA., Cardoso JC., Power DM., Peck LS. 2010. Insights into shell deposition in the Antarctic bivalve Laternula elliptica: gene discovery in the mantle transcriptome using 454 pyrosequencing. BMC Genomics 11:362. Noncoding Transcripts. PLOS ONE 9:e112420. 
437 D’Onofrio G., Mouchiroud D., Aïssani B., Gautier C., Bernardi G. 1991. Correlations between the

438 compositional properties of human genes, codon usage, and amino acid composition of $439 \quad$ proteins. Journal of Molecular Evolution 32:504-510.

440 Duret L. 2000. tRNA gene number and codon usage in the C. elegans genome are co-adapted for optimal translation of highly expressed genes. Trends in genetics: TIG 16:287-289.

Duret L., Mouchiroud D. 1999. Expression pattern and, surprisingly, gene length shape codon usage in Caenorhabditis, Drosophila, and Arabidopsis. Proceedings of the National Academy of Sciences 96:4482-4487.

Egas C., Pinheiro M., Gomes P., Barroso C., Bettencourt R. 2012. The Transcriptome of Bathymodiolus azoricus Gill Reveals Expression of Genes from Endosymbionts and Free-Living Deep-Sea Bacteria. Marine Drugs 10:1765-1783.

Ermolaeva MD. 2001. Synonymous codon usage in bacteria. Current Issues in Molecular Biology 3:91-97.

Eyre-Walker A. 1996. Synonymous codon bias is related to gene length in Escherichia coli: selection for translational accuracy? Molecular Biology and Evolution 13:864-872.

Fields PA., Eurich C., Gao WL., Cela B. 2014. Changes in protein expression in the salt marsh mussel Geukensia demissa: evidence for a shift from anaerobic to aerobic metabolism during prolonged aerial exposure. The Journal of Experimental Biology 217:1601-1612.

Fu X., Sun Y., Wang J., Xing Q., Zou J., Li R., Wang Z., Wang S., Hu X., Zhang L., Bao Z. 2014. Sequencingbased gene network analysis provides a core set of gene resource for understanding thermal adaptation in Zhikong scallop Chlamys farreri. Molecular Ecology Resources 14:184-198. sequencing and de novo assembly of the digestive gland transcriptome in Mytilus galloprovincialis fed with toxinogenic and non-toxic strains of Alexandrium minutum. $B M C$ research notes 7:722. 
461 Gerdol M., Venier P., Pallavicini A. 2014. The genome of the Pacific oyster Crassostrea gigas brings new

462

463

464

465

466

467

468

469

470

471

472

473

474

475

476

477

478

479

480

481

482

483 insights on the massive expansion of the C1q gene family in Bivalvia. Developmental and comparative immunology accepted:in press.

Ghiselli F., Milani L., Chang PL., Hedgecock D., Davis JP., Nuzhdin SV., Passamonti M. 2012. De Novo assembly of the Manila clam Ruditapes philippinarum transcriptome provides new insights into expression bias, mitochondrial doubly uniparental inheritance and sex determination. Molecular Biology and Evolution 29:771-786.

González VL., Andrade SCS., Bieler R., Collins TM., Dunn CW., Mikkelsen PM., Taylor JD., Giribet G. 2015. A phylogenetic backbone for Bivalvia: an RNA-seq approach. Proceedings of the Royal Society B: Biological Sciences 282.

Gosling EM. 2003. Bivalve Molluscs: Biology, Ecology and Culture. Oxford, UK.

Gouy M., Gautier C. 1982. Codon usage in bacteria: correlation with gene expressivity. Nucleic Acids Research 10:7055-7074.

Gribskov M., Devereux J., Burgess RR. 1984. The codon preference plot: graphic analysis of protein coding sequences and prediction of gene expression. Nucleic Acids Research 12:539-549.

Gu W., Zhou T., Ma J., Sun X., Lu Z. 2004. Analysis of synonymous codon usage in SARS Coronavirus and other viruses in the Nidovirales. Virus Research 101:155-161.

Hershberg R., Petrov DA. 2008. Selection on codon bias. Annual Review of Genetics 42:287-299.

Hiraoka Y., Kawamata K., Haraguchi T., Chikashige Y. 2009. Codon usage bias is correlated with gene expression levels in the fission yeast Schizosaccharomyces pombe. Genes to Cells: Devoted to Molecular \& Cellular Mechanisms 14:499-509.

de Hoon MJL., Imoto S., Nolan J., Miyano S. 2004. Open source clustering software. Bioinformatics (Oxford, England) 20:1453-1454. 
484 Ikemura T. 1985. Codon usage and tRNA content in unicellular and multicellular organisms. Molecular $485 \quad$ Biology and Evolution 2:13-34.

486 Jenkins GM., Holmes EC. 2003. The extent of codon usage bias in human RNA viruses and its evolutionary origin. Virus Research 92:1-7.

488

491

492

493

494

495

496

497

498

500

501

502

503

504

505

Jones DB., Jerry DR., Forêt S., Konovalov DA., Zenger KR. 2013. Genome-wide SNP validation and mantle tissue transcriptome analysis in the silver-lipped pearl oyster, Pinctada maxima. Marine Biotechnology (New York, N.Y.) 15:647-658.

Kliman RM., Hey J. 1994. The effects of mutation and natural selection on codon bias in the genes of Drosophila. Genetics 137:1049-1056.

Knight RD., Freeland SJ., Landweber LF. 2001. A simple model based on mutation and selection explains trends in codon and amino-acid usage and GC composition within and across genomes. Genome Biology 2:research0010.

Kober KM., Pogson GH. 2013. Genome-wide patterns of codon bias are shaped by natural selection in the purple sea urchin, Strongylocentrotus purpuratus. G3 (Bethesda, Md.) 3:1069-1083.

Marais G., Duret L. 2001. Synonymous codon usage, accuracy of translation, and gene length in Caenorhabditis elegans. Journal of Molecular Evolution 52:275-280.

Meng X., Liu M., Jiang K., Wang B., Tian X., Sun S., Luo Z., Qiu C., Wang L. 2013. De Novo Characterization of Japanese Scallop Mizuhopecten yessoensis Transcriptome and Analysis of Its Gene Expression following Cadmium Exposure. PLOS ONE 8.

Mitreva M., Wendl MC., Martin J., Wylie T., Yin Y., Larson A., Parkinson J., Waterston RH., McCarter JP. 2006. Codon usage patterns in Nematoda: analysis based on over 25 million codons in thirty-two species. Genome Biology 7:R75. 
506 Moreira R., Pereiro P., Canchaya C., Posada D., Figueras A., Novoa B. 2015. RNA-Seq in Mytilus

507 galloprovincialis: comparative transcriptomics and expression profiles among different tissues.

$508 \quad$ BMC Genomics 16:728.

509 Moriyama EN., Powell JR. 1997. Codon usage bias and tRNA abundance in Drosophila. Journal of

$510 \quad$ Molecular Evolution 45:514-523.

511 Moriyama EN., Powell JR. 1998. Gene length and codon usage bias in Drosophila melanogaster,

512 Saccharomyces cerevisiae and Escherichia coli. Nucleic Acids Research 26:3188-3193.

513 Muto A., Osawa S. 1987. The guanine and cytosine content of genomic DNA and bacterial evolution.

$514 \quad$ Proceedings of the National Academy of Sciences 84:166-169.

515 Nguyen TTT., Hayes BJ., Ingram BA. 2014. Genetic parameters and response to selection in blue mussel

516 (Mytilus galloprovincialis) using a SNP-based pedigree. Aquaculture 420-421:295-301.

517 Palidwor GA., Perkins TJ., Xia X. 2010. A general model of codon bias due to GC mutational bias. PloS

$518 \quad$ One 5:e13431.

519 Pauletto M., Milan M., Moreira R., Novoa B., Figueras A., Babbucci M., Patarnello T., Bargelloni L. 2014.

520 Deep transcriptome sequencing of Pecten maximus hemocytes: a genomic resource for bivalve $521 \quad$ immunology. Fish \& Shellfish Immunology 37:154-165.

522 Philipp EER., Wessels W., Gruber H., Strahl J., Wagner AE., Ernst IMA., Rimbach G., Kraemer L., Schreiber

523 S., Abele D., Rosenstiel P. 2012. Gene expression and physiological changes of different

524 populations of the long-lived bivalve Arctica islandica under low oxygen conditions. PloS One

$525 \quad 7: e 44621$.

526 Plotkin JB., Kudla G. 2011. Synonymous but not the same: the causes and consequences of codon bias.

$527 \quad$ Nature Reviews Genetics 12:32-42.

528 Powell JR., Moriyama EN. 1997. Evolution of codon usage bias in Drosophila. Proceedings of the National 529 Academy of Sciences 94:7784-7790. 
530 Prentis PJ., Pavasovic A. 2014. The Anadara trapezia transcriptome: A resource for molluscan

531 physiological genomics. Marine Genomics 18, Part B:113-115.

532 Qin J., Huang Z., Chen J., Zou Q., You W., Ke C. 2012. Sequencing and de novo analysis of Crassostrea angulata (Fujian oyster) from 8 different developing phases using 454 GSFIx. PloS One 7:e43653.

Rice P., Longden I., Bleasby A. 2000. EMBOSS: the European Molecular Biology Open Software Suite. Trends in genetics: TIG 16:276-277.

Sauvage C., Bierne N., Lapègue S., Boudry P. 2007. Single Nucleotide polymorphisms and their relationship to codon usage bias in the Pacific oyster Crassostrea gigas. Gene 406:13-22.

Sémon M., Lobry JR., Duret L. 2006. No Evidence for Tissue-Specific Adaptation of Synonymous Codon Usage in Humans. Molecular Biology and Evolution 23:523-529.

Sharp PM., Stenico M., Peden JF., Lloyd AT. 1993. Codon usage: mutational bias, translational selection, or both? Biochemical Society Transactions 21:835-841.

Sharp PM., Emery LR., Zeng K. 2010. Forces that influence the evolution of codon bias. Philosophical Transactions of the Royal Society of London. Series B, Biological Sciences 365:1203-1212.

Sharp PM., Li WH. 1987. The codon Adaptation Index--a measure of directional synonymous codon usage bias, and its potential applications. Nucleic Acids Research 15:1281-1295.

Sharp PM., Tuohy TM., Mosurski KR. 1986. Codon usage in yeast: cluster analysis clearly differentiates Populations of the European Clam Ruditapes decussatus. PLOS ONE 9.

Stenico M., Lloyd AT., Sharp PM. 1994. Codon usage in Caenorhabditis elegans: delineation of translational selection and mutational biases. Nucleic Acids Research 22:2437-2446. 
553 Suárez-Ulloa V., Fernández-Tajes J., Manfrin C., Gerdol M., Venier P., Eirín-López JM. 2013. Bivalve

554 Omics: State of the Art and Potential Applications for the Biomonitoring of Harmful Marine

$555 \quad$ Compounds. Marine Drugs 11:4370-4389.

556 Sueoka N., Kawanishi Y. 2000. DNA G+C content of the third codon position and codon usage biases of 557 human genes. Gene 261:53-62.

558 Takeuchi T., Kawashima T., Koyanagi R., Gyoja F., Tanaka M., Ikuta T., Shoguchi E., Fujiwara M., Shinzato C., Hisata K., Fujie M., Usami T., Nagai K., Maeyama K., Okamoto K., Aoki H., Ishikawa T., Masaoka T., Fujiwara A., Endo K., Endo H., Nagasawa H., Kinoshita S., Asakawa S., Watabe S., Satoh N. 2012. Draft genome of the pearl oyster Pinctada fucata: a platform for understanding

Vicario S., Moriyama EN., Powell JR. 2007. Codon usage in twelve species of Drosophila. BMC Evolutionary Biology 7:226. Biowissenschaften 131:281-285.

Wan X-F., Xu D., Kleinhofs A., Zhou J. 2004. Quantitative relationship between synonymous codon usage Wagner GP., Kin K., Lynch VJ. 2012. Measurement of mRNA abundance using RNA-seq data: RPKM bias and GC composition across unicellular genomes. BMC Evolutionary Biology 4:19.

Wright F. 1990. The "effective number of codons" used in a gene. Gene 87:23-29.

Wu G., Culley DE., Zhang W. 2005. Predicted highly expressed genes in the genomes of Streptomyces coelicolor and Streptomyces avermitilis and the implications for their metabolism. Microbiology (Reading, England) 151:2175-2187.

Xie T., Ding D., Tao X., Dafu D. 1998. The relationship between synonymous codon usage and protein structure. FEBS letters 434:93-96. 
Zapata F., Wilson NG., Howison M., Andrade SCS., Jörger KM., Schrödl M., Goetz FE., Giribet G., Dunn CW. 2014. Phylogenomic analyses of deep gastropod relationships reject Orthogastropoda. Proceedings of the Royal Society of London B: Biological Sciences 281:20141739.

Zeeberg B. 2002. Shannon information theoretic computation of synonymous codon usage biases in coding regions of human and mouse genomes. Genome Research 12:944-955.

Zhang G., Fang X., Guo X., Li L., Luo R., Xu F., Yang P., Zhang L., Wang X., Qi H., Xiong Z., Que H., Xie Y., Holland PWH., Paps J., Zhu Y., Wu F., Chen Y., Wang J., Peng C., Meng J., Yang L., Liu J., Wen B., Zhang N., Huang Z., Zhu Q., Feng Y., Mount A., Hedgecock D., Xu Z., Liu Y., Domazet-Lošo T., Du Y., Sun X., Zhang S., Liu B., Cheng P., Jiang X., Li J., Fan D., Wang W., Fu W., Wang T., Wang B., Zhang J., Peng Z., Li Y., Li N., Wang J., Chen M., He Y., Tan F., Song X., Zheng Q., Huang R., Yang H., Du X., Chen L., Yang M., Gaffney PM., Wang S., Luo L., She Z., Ming Y., Huang W., Zhang S., Huang B., Zhang Y., Qu T., Ni P., Miao G., Wang J., Wang Q., Steinberg CEW., Wang H., Li N., Qian L., Zhang G., Li Y., Yang H., Liu X., Wang J., Yin Y., Wang J. 2012. The oyster genome reveals stress adaptation and complexity of shell formation. Nature 490:49-54.

Zhang L., Li L., Zhu Y., Zhang G., Guo X. 2014. Transcriptome analysis reveals a rich gene set related to innate immunity in the Eastern oyster (Crassostrea virginica). Marine Biotechnology (New York, N.Y.) 16:17-33.

Zhao C., Zhang T., Zhang X., Hu S., Xiang J. 2012. Sequencing and analysis of four BAC clones containing innate immune genes from the Zhikong scallop (Chlamys farreri). Gene 502:9-15.

Zhao X., Yu H., Kong L., Liu S., Li Q. 2014. Comparative Transcriptome Analysis of Two Oysters, Crassostrea gigas and Crassostrea hongkongensis Provides Insights into Adaptation to HypoOsmotic Conditions. PLOS ONE 9:e111915. 
600 Figures 
A.

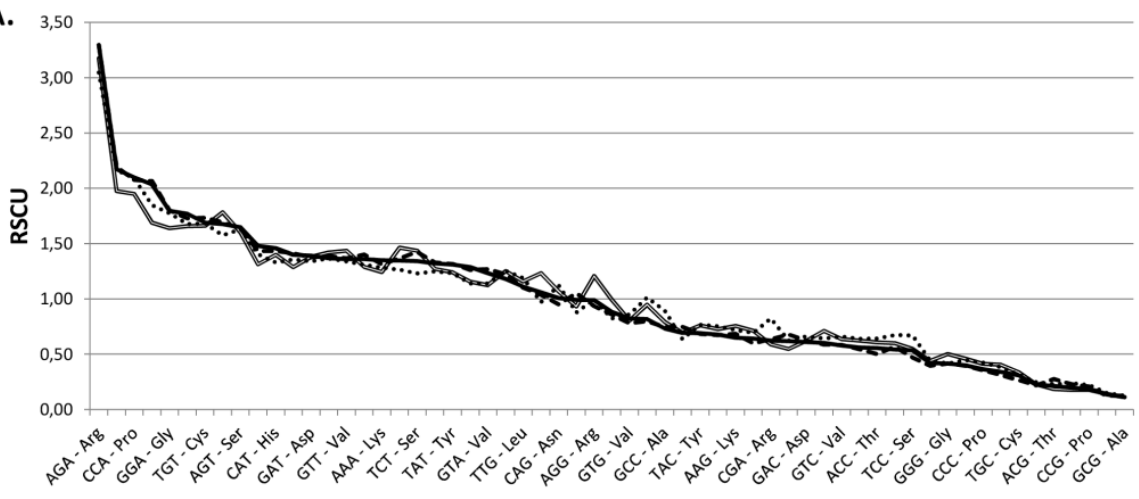

Mytilus galloprovincialis $\quad---$ Bathymodiolus platifrons $\quad \cdots . .$. Geukensia demissa $\longrightarrow$ Perna viridis

B.

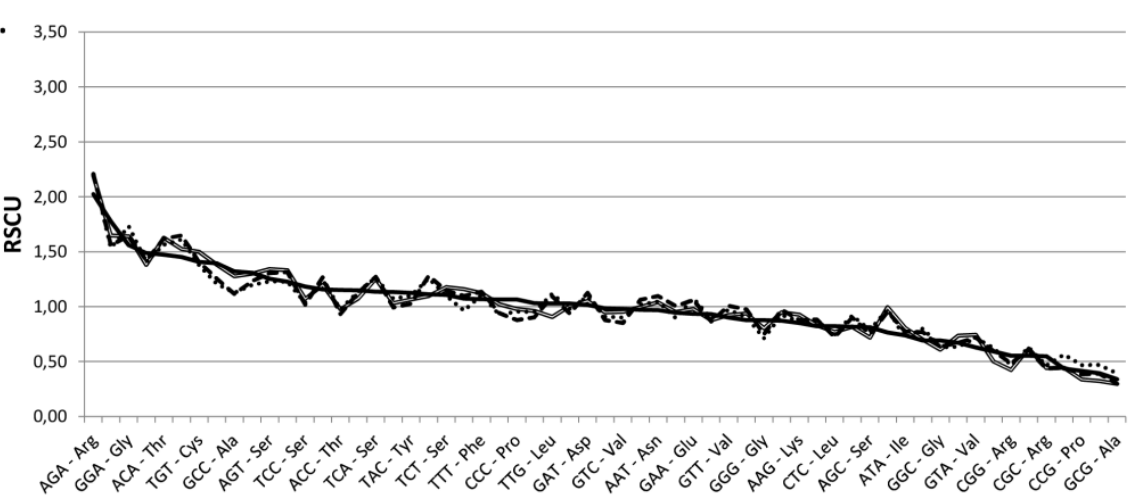

C.

Crassostrea gigas $\quad$ - O Ostrea edulis $\quad . . .$. Ostreola stentina $\quad$ Saccostrea glomerata

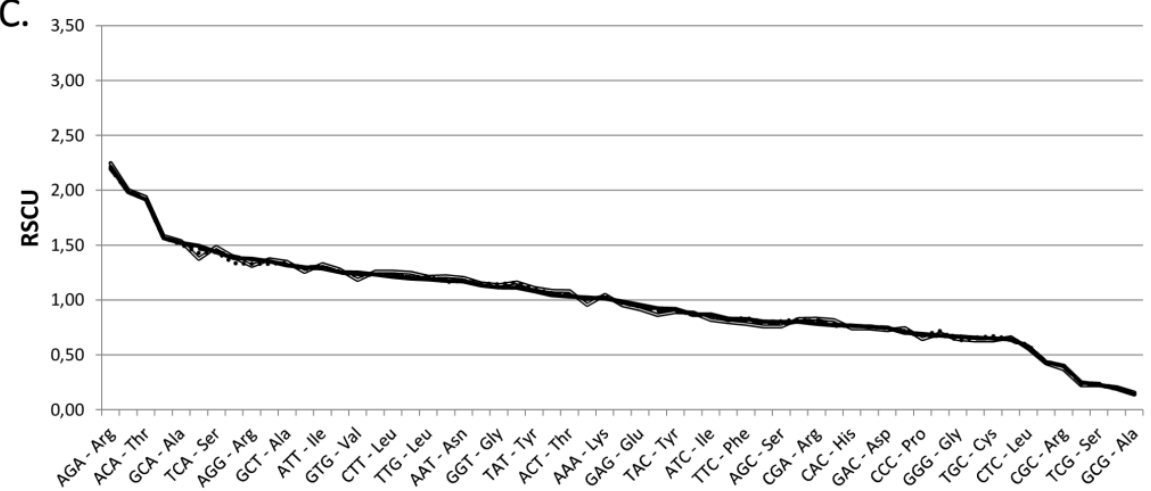

—Elliptio complanata $\quad$ - - Uniomerus tetralasmus $\quad . . .$. Villosa lienosa $\quad$ Pyganodon grandis

D.

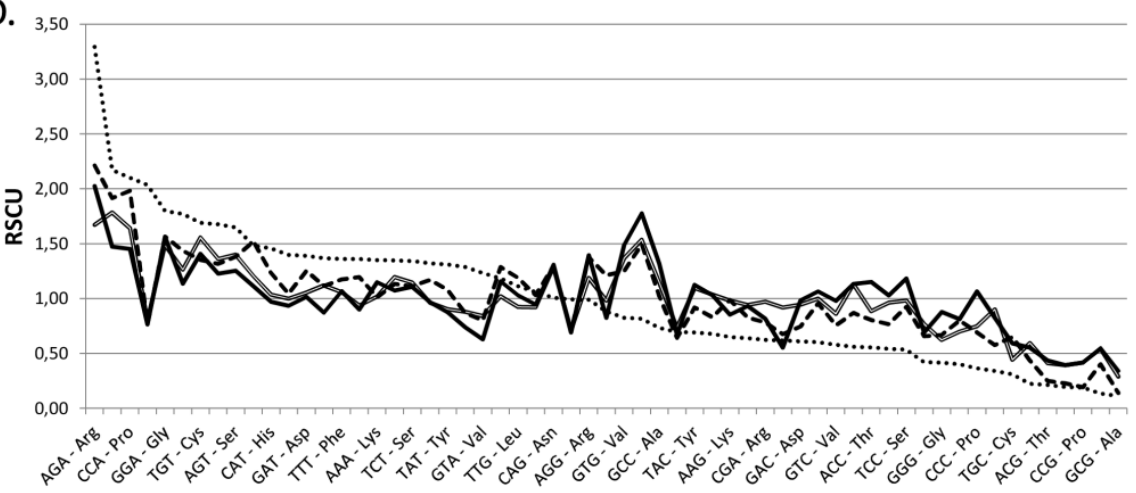


602 Figure 1: RSCU values (Y axis) in four Mytilida (panel A), Ostreoidea (panel B) and Unionida 603 (panel C) species. Panel D shows a comparison between representative species from the three 604 above mentioned orders and the Pectinida Pecten maximus. Codons are ordered by decreasing 605 RSCU value on the X axis, based on Mytilus galloprovincialis (panels A and D), Crassostrea 606 gigas (panel B) and Elliptio complanata (panel C). 


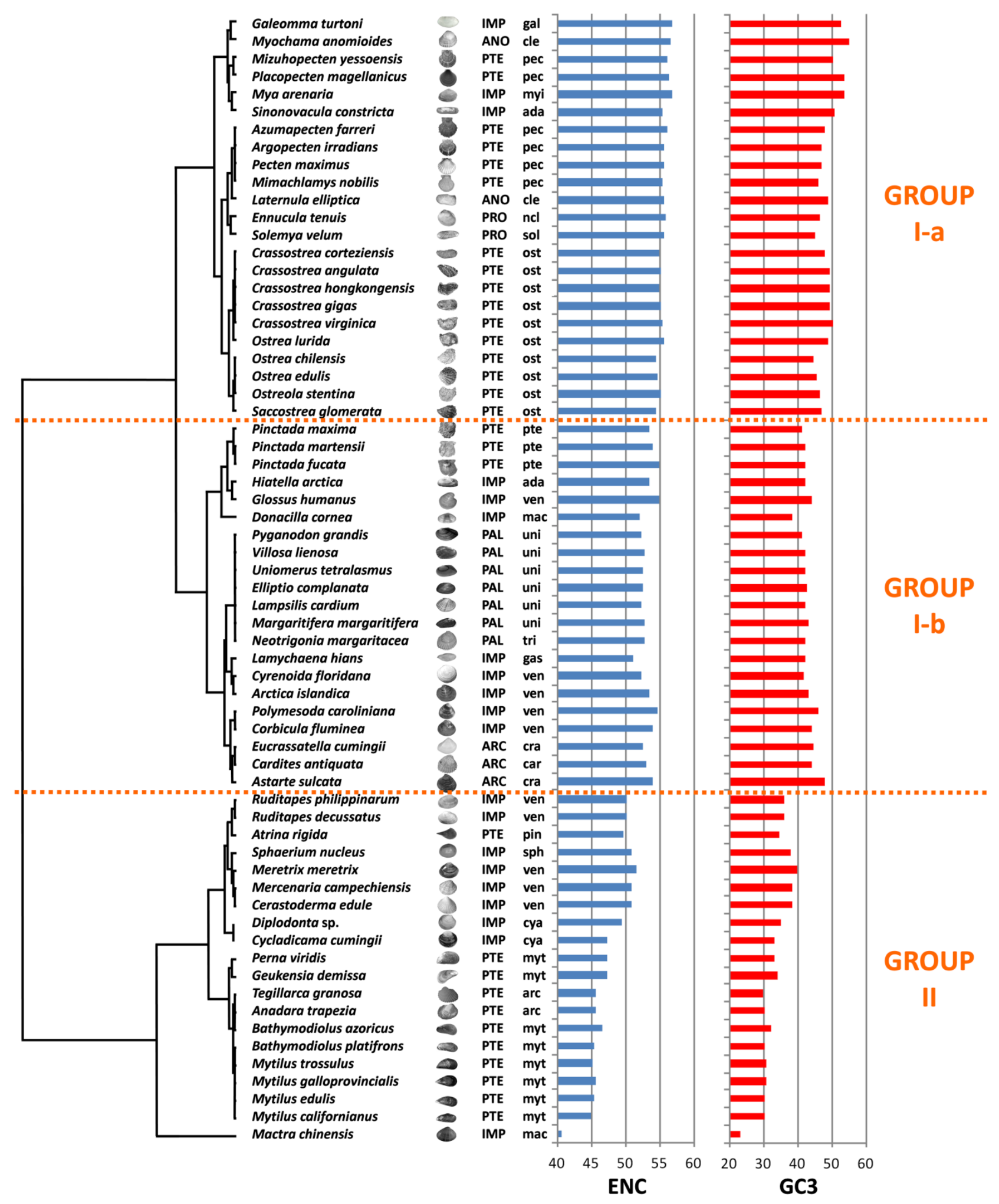


609 Figure 2. Clustering of bivalve species according to the variation of codon usage. The 610 dendrogram was inferred with Cluster 3 by hierarchical clustering, using Euclidean distance as a 611 similarity metric and an average linkage clustering method. Effective number of codons (ENC) 612 and $\mathrm{GC}_{3}$ metric for each species are also displayed. A three letter code near the species name 613 indicates the taxonomical classification according to Bieler et al. (2014). In detail, capital letters 614 identify one of the six major evolutionary lineages and lowercase letters identify the order. ARC: 615 Archiheterodonta; ANO: Anomalodesmata; IMP: Imparidentia; PAL: Palaeoheterodonta; PRO: 616 Protobranchia; PTE: Pteriomorphia; ada: Adapedonta; arc: Arcida; car: Carditoidea; cle: 617 Cleidothaeridae; cra: Crassatelloidea; cya: Cyamioidea; gal: Galeommatoidea; gas: 618 Gastrochaenidae; mac: Mactroidea; myi: Myida; myt: Mytilida; ncl: Nuculoidea; pec: Pectinida; 619 pin: Pinnoidea; pte: Pterioidea; ost: Ostreoidea; sol: Solemyoidea; sph: Sphaerioidea; tri: 620 Trigoniida; uni: Unionida; ven: Veneroidea. 
A.

\begin{tabular}{|c|c|c|c|c|}
\hline preferred & A & $\mathrm{T}$ & $\mathrm{C}$ & $\mathrm{G}$ \\
\hline \multirow{2}{*}{ AA } & 54 & 48 & 16 & 10 \\
\hline & Lys & Asn & Asn & Lys \\
\hline \multirow{2}{*}{ AT } & 28 & 58 & 19 & 1 \\
\hline & Ile & Ile & Ile & Met \\
\hline \multirow{2}{*}{$A C$} & 64 & 25 & 9 & 0 \\
\hline & Thr & Thr & Thr & Thr \\
\hline \multirow{2}{*}{ AG } & 64 & 64 & 0 & 44 \\
\hline & Arg & Ser & Ser & Arg \\
\hline \multirow{2}{*}{ TA } & / & 39 & 25 & I \\
\hline & STOP & Tyr & Tyr & STOP \\
\hline \multirow{2}{*}{ TT } & 28 & 59 & 5 & 52 \\
\hline & Leu & Phe & Phe & Leu \\
\hline \multirow{2}{*}{ TC } & 64 & 60 & 17 & 0 \\
\hline & Ser & Ser & Ser & Ser \\
\hline \multirow{2}{*}{ TG } & / & 64 & 0 & / \\
\hline & STOP & Cys & Cys & Trp \\
\hline \multirow{2}{*}{ CA } & 4 & 54 & 10 & 60 \\
\hline & Gln & His & $\mathrm{His}$ & Gln \\
\hline \multirow{2}{*}{ CT } & 0 & 19 & 2 & 49 \\
\hline & Leu & Leu & Leu & Leu \\
\hline \multirow{2}{*}{ CC } & 64 & 57 & 7 & 0 \\
\hline & Pro & Pro & Pro & Pro \\
\hline \multirow{2}{*}{ CG } & 3 & 4 & 0 & 0 \\
\hline & Arg & Arg & Arg & Arg \\
\hline \multirow{2}{*}{ GA } & 49 & 60 & 4 & 14 \\
\hline & Glu & Asp & Asp & Glu \\
\hline \multirow{2}{*}{ GT } & 21 & 42 & 1 & 52 \\
\hline & Val & Val & Val & Val \\
\hline \multirow{2}{*}{ GC } & 63 & 64 & 35 & 0 \\
\hline & Ala & Ala & Ala & Ala \\
\hline \multirow{2}{*}{ GG } & 64 & 52 & 2 & 0 \\
\hline & Gly & Gly & Gly & Gly \\
\hline
\end{tabular}

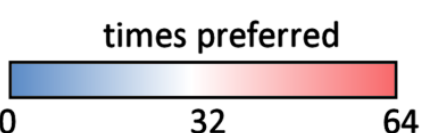

B.

\begin{tabular}{|c|c|c|c|c|}
\hline - ENC & A & $\mathrm{T}$ & C & G \\
\hline \multirow{2}{*}{ AA } & 0,86 & 0,9 & $-0,9$ & $-0,86$ \\
\hline & Lys & Asn & Asn & Lys \\
\hline \multirow{2}{*}{ AT } & 0,82 & 0,34 & $-0,92$ & / \\
\hline & Ile & Ile & Ile & Met \\
\hline \multirow{2}{*}{$A C$} & 0,84 & 0,71 & $-0,87$ & $-0,77$ \\
\hline & Thr & Thr & Thr & Thr \\
\hline \multirow{2}{*}{$A G$} & 0,95 & 0,9 & $-0,89$ & $-0,59$ \\
\hline & Arg & Ser & Ser & Arg \\
\hline \multirow{2}{*}{ TA } & / & 0,94 & $-0,94$ & I \\
\hline & STOP & Tyr & Tyr & STOP \\
\hline \multirow{2}{*}{$\pi T$} & 0,93 & 0,91 & $-0,91$ & 0,24 NS \\
\hline & Leu & Phe & Phe & Leu \\
\hline \multirow{2}{*}{$\mathrm{TC}$} & 0,91 & 0,84 & $-0,88$ & $-0,76$ \\
\hline & Ser & Ser & Ser & Ser \\
\hline \multirow{2}{*}{ TG } & I & 0,75 & $-0,75$ & / \\
\hline & STOP & Cys & Cys & Trp \\
\hline \multirow{2}{*}{ CA } & 0,85 & 0,91 & $-0,91$ & $-0,85$ \\
\hline & Gln & His & His & Gln \\
\hline \multirow{2}{*}{$\mathrm{CT}$} & $0,1 \mathrm{NS}$ & 0,2 NS & $-0,92$ & $-0,91$ \\
\hline & Leu & Leu & Leu & Leu \\
\hline \multirow{2}{*}{$\mathrm{CC}$} & 0,79 & 0,68 & $-0,87$ & $-0,73$ \\
\hline & Pro & Pro & Pro & Pro \\
\hline \multirow{2}{*}{ CG } & $-0,79$ & $-0,11 \mathrm{NS}$ & $-0,88$ & $-0,87$ \\
\hline & Arg & Arg & Arg & Arg \\
\hline \multirow{2}{*}{$\mathrm{GA}$} & 0,93 & 0,92 & $-0,92$ & $-0,93$ \\
\hline & Glu & Asp & Asp & Glu \\
\hline \multirow{2}{*}{ GT } & 0,85 & 0,9 & $-0,86$ & $-0,93$ \\
\hline & Val & Val & Val & Val \\
\hline \multirow{2}{*}{ GC } & 0,58 & 0,86 & $-0,89$ & $-0,78$ \\
\hline & Ala & Ala & Ala & Ala \\
\hline \multirow{2}{*}{ GG } & 0,54 & 0,75 & $-0,86$ & $-0,83$ \\
\hline & Gly & Gly & Gly & Gly \\
\hline
\end{tabular}

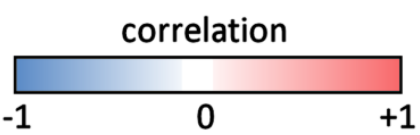

621

622 Figure 3: Panel A: number of bivalve species (out of the 64 selected for this study) where a

623 given codon was preferred $(\mathrm{RSCU}>1)$. Panel B: Paerson correlation coefficient between the

624 frequency of each codon and overall species CUB (negative ENC); NS = non-significant

625 correlation, based on F-test of linear regression. 


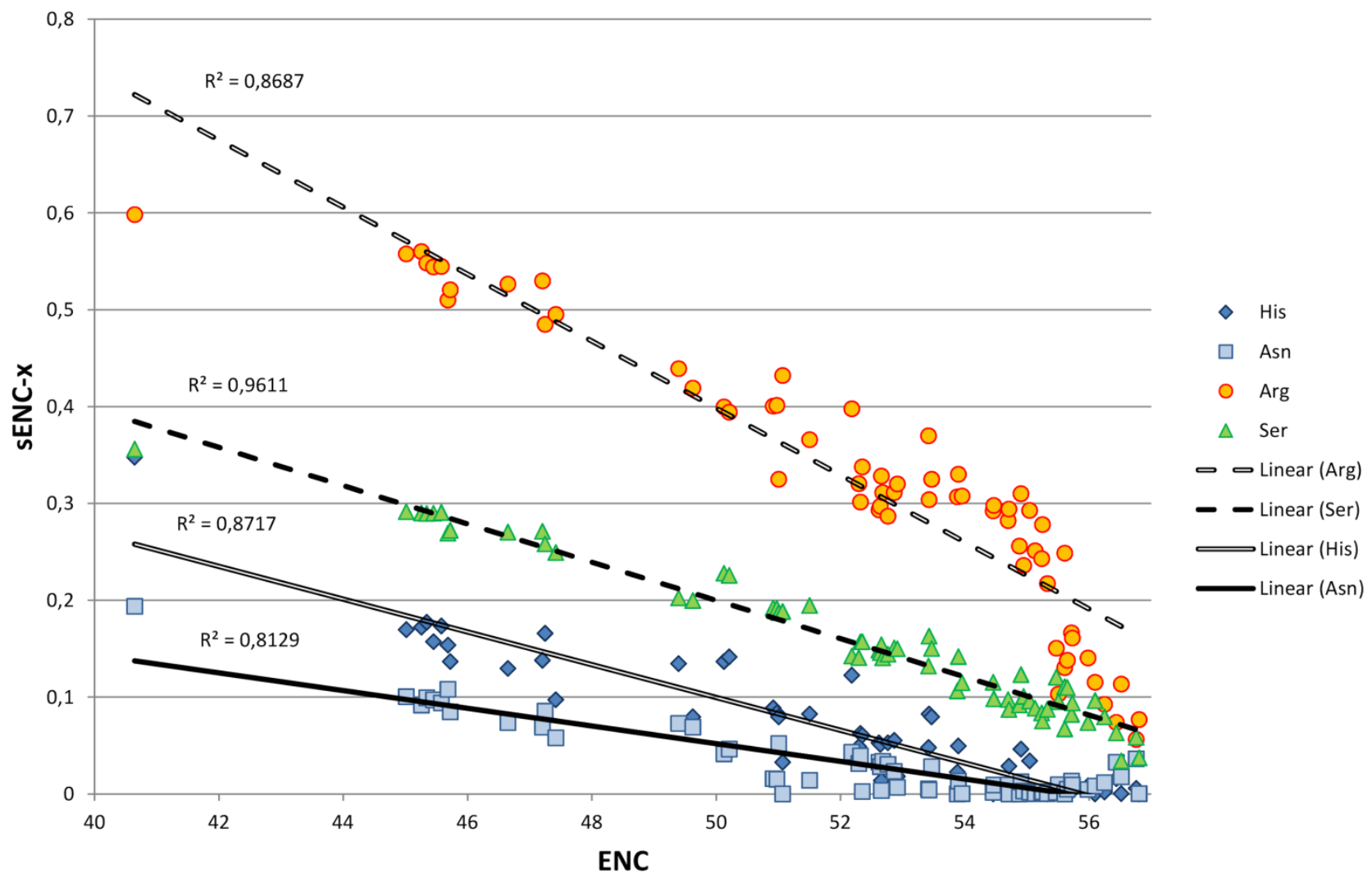

626

627 Figure 4. Simple linear regression analysis exemplifying the different contribution of four amino

628 acids (Asn, Arg, Ser and His) to synonymous codon usage bias. ENC values for each species are

629 plotted on the $\mathrm{X}$ axis and represent a measure of synonymous codon usage (lower ENC values

630 indicate a stronger $\mathrm{CUB}$ ). sENC-x values are plotted on the $\mathrm{Y}$ axis and represent the relative

631 intensity of CUB for each amino acid in each species. R squared correlation values are shown for

632 each regression line. Detailed data for all amino acids are reported in Table S5. 


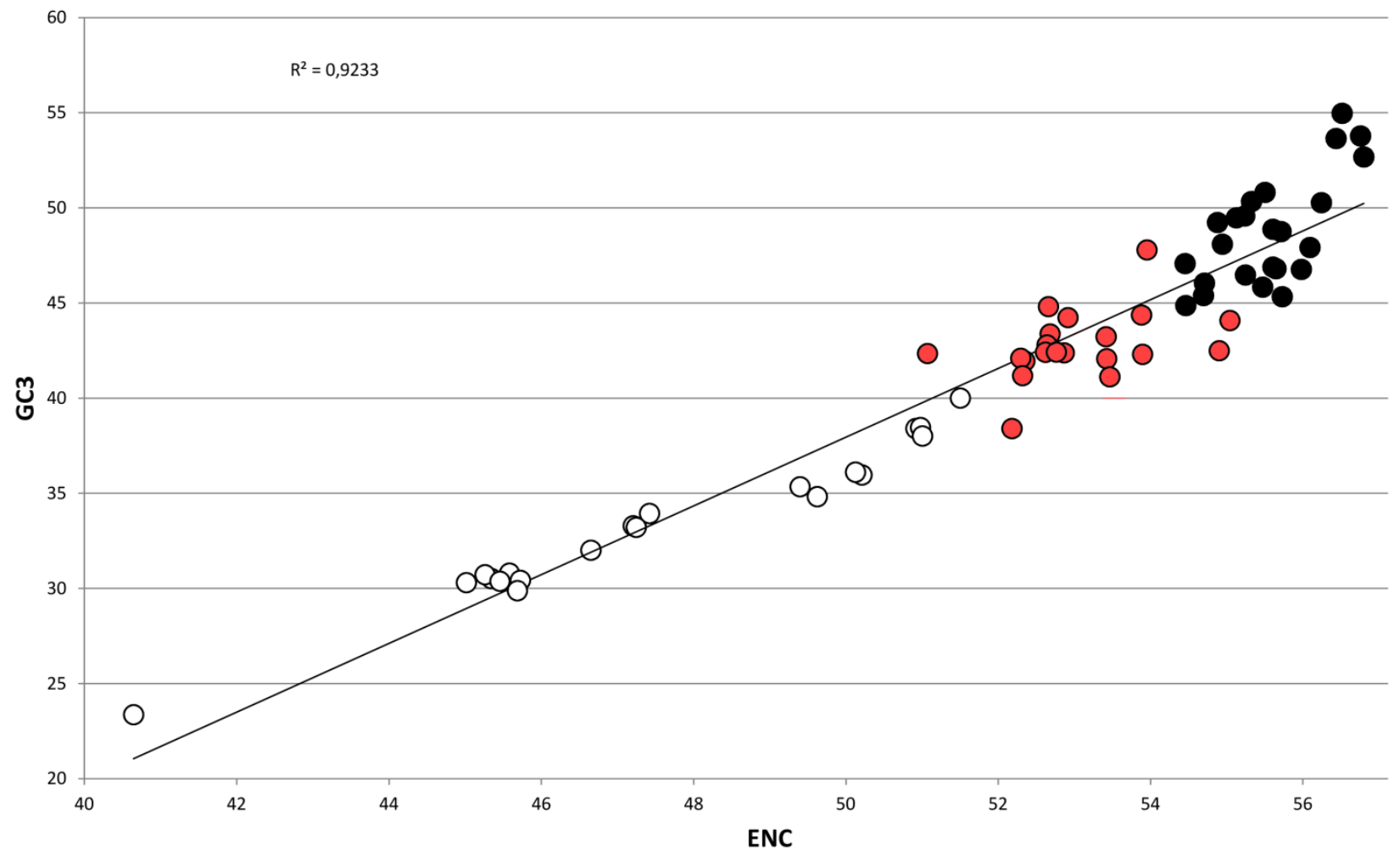

634 Figure 5. Regression line defining the correlation between $\mathrm{ENC}$ and $\mathrm{GC}_{3}$ in bivalve species.

635 Species pertaining to the bivalve clustering group Ia, Ib and II (see Figure 2) are marked as

636 black, red and white circles, respectively. The P-value of the F-test of linear regression is $6372.86 \times 10^{-36}$. 

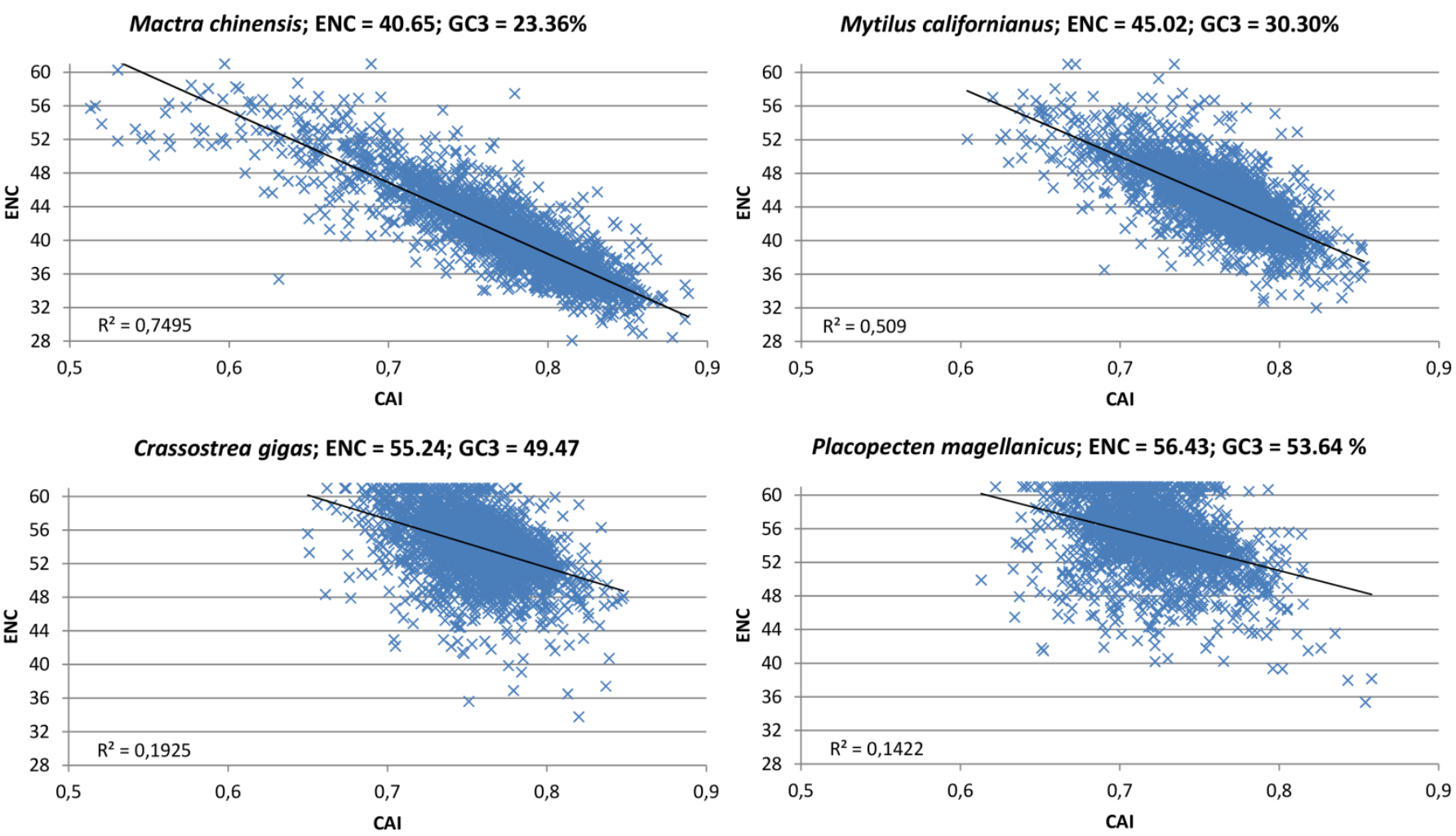

638

639 Figure 6. Scatter plot of CAI (X axis) vs ENC (Y axis) for four representative bivalve species:

640 Mactra chinensis, Mytilus californianus, Crassostrea gigas and Placopecten magellanicus. The

641 reference set of highly expressed genes for each species is based on the orthologous genes of $C$.

642 gigas (see Materials and methods). 


\section{Tables}

\begin{tabular}{|c|c|c|c|}
\hline Species & & sification * & ENC \\
\hline Galeomma turtoni & Imparidentia & Galeommatoidea & 56.80 \\
\hline Mya arenaria & Imparidentia & Myidae & 56.76 \\
\hline Myochama anomioides & Anomalodesmata & Cleidothaeridae & 56.52 \\
\hline Placopecten magellanicus & Pteriomorphia & Pectinida & 56.44 \\
\hline Mizuhopecten yessoensis & Pteriomorphia & Pectinida & 56.25 \\
\hline Azumapecten farreri & Pteriomorphia & Pectinida & 56.10 \\
\hline Ennucula tenuis & Protobranchia & Nuculoidea & 55.98 \\
\hline Solemya velum & Protobranchia & Solemyoidea & 55.73 \\
\hline Laternula elliptica & Anomalodesmata & Cleidothaeridae & 55.72 \\
\hline Argopecten irradians & Pteriomorphia & Pectinida & 55.65 \\
\hline Ostrea lurida & Pteriomorphia & Ostreoidea & 55.61 \\
\hline Pecten maximus & Pteriomorphia & Pectinida & 55.61 \\
\hline Sinonovacula constricta & Imparidentia & Adapedonta & 55.51 \\
\hline Mimachlamys nobilis & Pteriomorphia & Pectinida & 55.47 \\
\hline Crassostrea virginica & Pteriomorphia & Ostreoidea & 55.33 \\
\hline Ostreola stentina & Pteriomorphia & Ostreoidea & 55.25 \\
\hline Crassostrea gigas & Pteriomorphia & Ostreoidea & 55.24 \\
\hline Crassostrea angulata & Pteriomorphia & Ostreoidea & 55.13 \\
\hline Glossus humanus & Imparidentia & Venerida & 55.04 \\
\hline Crassostrea corteziensis & Pteriomorphia & Ostreoidea & 54.95 \\
\hline Pinctada fucata & Pteriomorphia & Pterioidea & 54.90 \\
\hline Crassostrea hongkongensis & Pteriomorphia & Ostreoidea & 54.88 \\
\hline Polymesoda caroliniana & Imparidentia & Venerida & 54.71 \\
\hline Ostrea edulis & Pteriomorphia & Ostreoidea & 54.70 \\
\hline Ostrea chilensis & Pteriomorphia & Ostreoidea & 54.46 \\
\hline Saccostrea glomerata & Pteriomorphia & Ostreoidea & 54.46 \\
\hline Astarte sulcata & Archiheterodonta & Crassatelloidea & 53.95 \\
\hline Pinctada martensi & Pteriomorphia & Pterioidea & 53.89 \\
\hline Corbicula fluminea & Imparidentia & Venerida & 53.88 \\
\hline Pinctada maxima & Pteriomorphia & Pterioidea & 53.47 \\
\hline Hiatella arctica & Imparidentia & Adapedonta & 53.42 \\
\hline Arctica islandica & Imparidentia & Venerida & 53.42 \\
\hline Cardites antiquata & Archiheterodonta & Carditoidea & 52.92 \\
\hline Neotrigonia margaritacea & Palaeoheterodonta & Trigoniida & 52.87 \\
\hline Villosa lienosa & Palaeoheterodonta & Unionida & 52.76 \\
\hline Margaritifera margatifera & Palaeoheterodonta & Unionida & 52.68 \\
\hline Eucrassatella cumingii & Archiheterodonta & Crassatelloidea & 52.66 \\
\hline Ellipto complanata & Palaeoheterodonta & Unionida & 52.64 \\
\hline Uniomerus tetralasmus & Palaeoheterodonta & Unionida & 52.62 \\
\hline
\end{tabular}




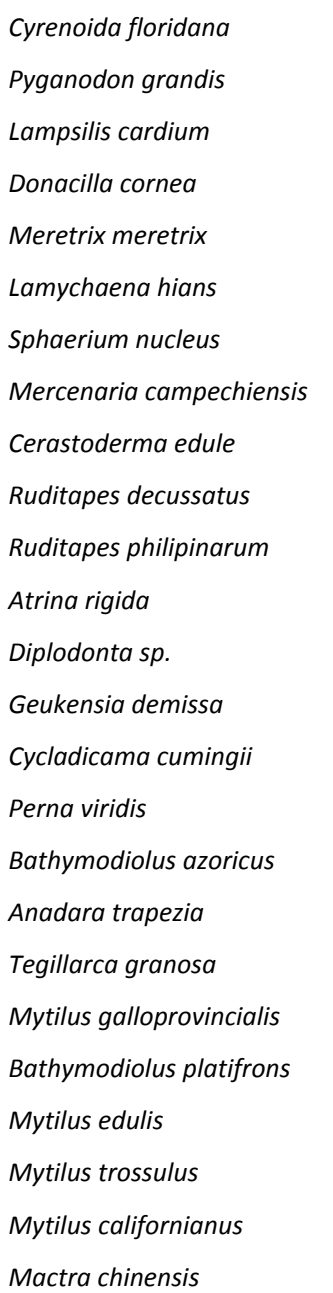

Imparidentia
Palaeoheterodonta
Palaeoheterodonta
Imparidentia
Imparidentia
Imparidentia
Imparidentia
Imparidentia
Imparidentia
Imparidentia
Imparidentia
Pteriomorphia
Imparidentia
Pteriomorphia
Imparidentia
Pteriomorphia
Pteriomorphia
Pteriomorphia
Pteriomorphia
Pteriomorphia
Pteriomorphia
Imparidentia

$\begin{array}{ll}\text { Venerida } & 52.35 \\ \text { Unionida } & 52.32 \\ \text { Unionida } & 52.29 \\ \text { Mactroidea } & 52.18 \\ \text { Venerida } & 51.50 \\ \text { Gastrochaenidae } & 51.07 \\ \text { Sphaeriidae } & 51.01 \\ \text { Venerida } & 50.98 \\ \text { Venerida } & 50.92 \\ \text { Venerida } & 50.21 \\ \text { Venerida } & 50.13 \\ \text { Pinnoidea } & 49.62 \\ \text { Cyamiidae } & 49.40 \\ \text { Mytilida } & 47.42 \\ \text { Cyamiidae } & 47.25 \\ \text { Mytilida } & 47.21 \\ \text { Mytilida } & 46.65 \\ \text { Arcida } & 45.72 \\ \text { Arcida } & 45.69 \\ \text { Mytilida } & 45.58 \\ \text { Mytilida } & 45.46 \\ \text { Mytilida } & 45.34 \\ \text { Mytilida } & 45.26 \\ \text { Mytilida } & 45.02 \\ \text { Mactroidea } & 40.65\end{array}$

645 Table 1. Effective number of codons (ENC) values in bivalves, ordered from the least to the 646 most biased species. * based on the revised classification of bivalves by Bieler et al. (2014). 
Crassostrea gigas

$$
\text { Coding } \mathrm{GC}_{3}
$$

Global ENC

Genomic GC content

Mutational bias

Correlation between CUB and protein length

Correlation between $\mathrm{GC}_{3}$ and protein length

Selection for translational accuracy

Correlation between CUB and gene expression (hemocytes)

Correlation between $\mathrm{GC}_{3}$ and gene expression (hemocytes)

Correlation between CUB and gene expression (digestive gland)

Correlation between $\mathrm{GC}_{3}$ and gene expression (digestive gland)

Correlation between CUB and gene expression (gills)

Correlation between $\mathrm{GC}_{3}$ and gene expression (gills)

Selection for translational speed

Correlation between CUB and GC3

Prevailing factor at the whole protein-coding transcriptome scale

$49.27 \%$

55.24

$33.69 \%$

towards A/T-ending codons

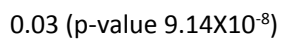

0.05 ( $p$-value 9.69X10-18)

towards G/C-ending codons

0.04 ( $p$-value $8.99 \times 10^{-12}$ )

0.03 ( $p$-value $1.44 \times 10^{-9}$ )

0.05 ( $p$-value $1.16 \times 10^{-17}$ )

0.06 ( $p$-value $1.04 \times 10^{-20}$ )

0.07 ( $p$-value $4.20 \times 10^{-29}$ )

0.06 ( $p$-value $6.14 \times 10^{-23}$ )

towards $\mathrm{G} / \mathrm{C}$-ending codons

-0.16 ( $p$-value $5.42 \times 10^{-148}$ )

mutational bias
Mytilus galloprovincialis

$30.80 \%$

45.58

$31.65 \%$

towards $\mathrm{A} / \mathrm{T}$-ending codons

0.09 ( $p$-value $3.75 \times 10^{-18}$ )

$-0.10\left(p\right.$-value $\left.5.43 \times 10^{-22}\right)$

towards $\mathrm{A} / \mathrm{T}$-ending codons

0 (NS)

0.07 (p-value 3.99X10-11)

0 (NS)

0.11 (p-value $2.67 \times 10^{-24}$ )

0 (NS)

0.12 ( $p$-value $1.04 \times 10^{-28}$ )

towards G/C-ending codons

-0.53 (p-value 0)

Mutational bias and selection for translational accuracy

648

649 Table 2. Influence of mutational bias and selection on codon usage bias in Crassostrea gigas and 650 Mytilus galloprovincialis. Paerson correlation coefficients and p-values of F-test for linear regression analysis are shown. 
1

Relative synonymous codon usage across bivalves

RSCU values ( $Y$ axis) in four Mytilida (panel A), Ostreoidea (panel B) and Unionida (panel C) species. Panel $D$ shows a comparison between representative species from the three above mentioned orders and the Pectinida Pecten maximus. Codons are ordered by decreasing RSCU value on the $X$ axis, based on Mytilus galloprovincialis (panels A and D), Crassostrea gigas (panel B) and Elliptio complanata (panel C). 

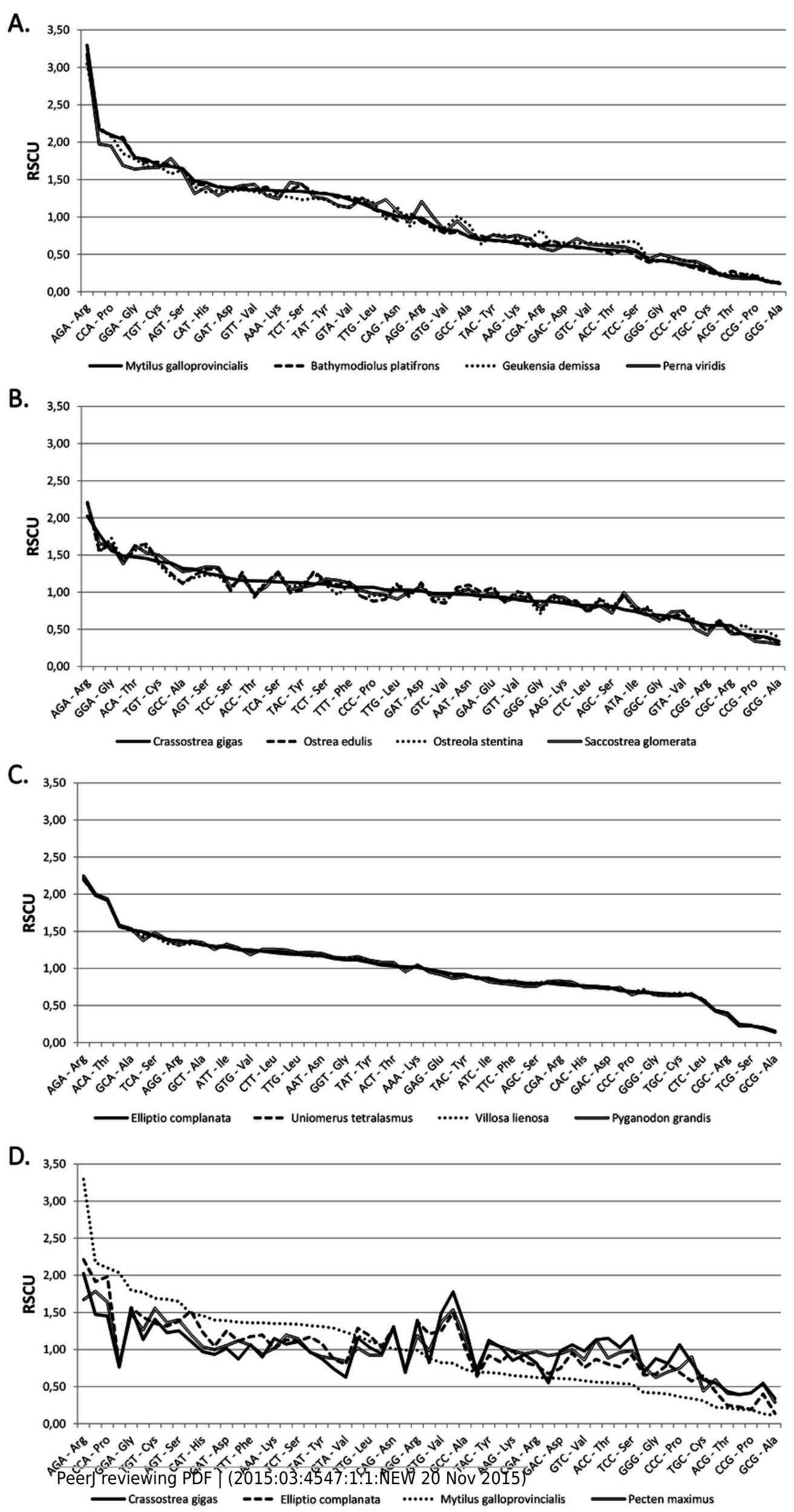
2

Clustering of bivalve species according to the variation of codon usage

The dendrogram was inferred with Cluster 3 by hierarchical clustering, using Euclidean distance as a similarity metric and an average linkage clustering method. Effective number of codons (ENC) and $\mathrm{GC}_{3}$ metric for each species are also displayed. $\mathrm{A}$ three letter code near the species name indicates the taxonomical classification according to Bieler et al. (2014). In detail, capital letters identify one of the six major evolutionary lineages and lowercase letters identify the order. ARC: Archiheterodonta; ANO: Anomalodesmata; IMP: Imparidentia; PAL: Palaeoheterodonta; PRO: Protobranchia; PTE: Pteriomorphia; ada: Adapedonta; arc: Arcida; car: Carditoidea; cle: Cleidothaeridae; cra: Crassatelloidea; cya: Cyamioidea; gal: Galeommatoidea; gas: Gastrochaenidae; mac: Mactroidea; myi: Myida; myt: Mytilida; ncl: Nuculoidea; pec: Pectinida; pin: Pinnoidea; pte: Pterioidea; ost: Ostreoidea; sol: Solemyoidea; sph: Sphaerioidea; tri: Trigoniida; uni: Unionida; ven: Veneroidea. 


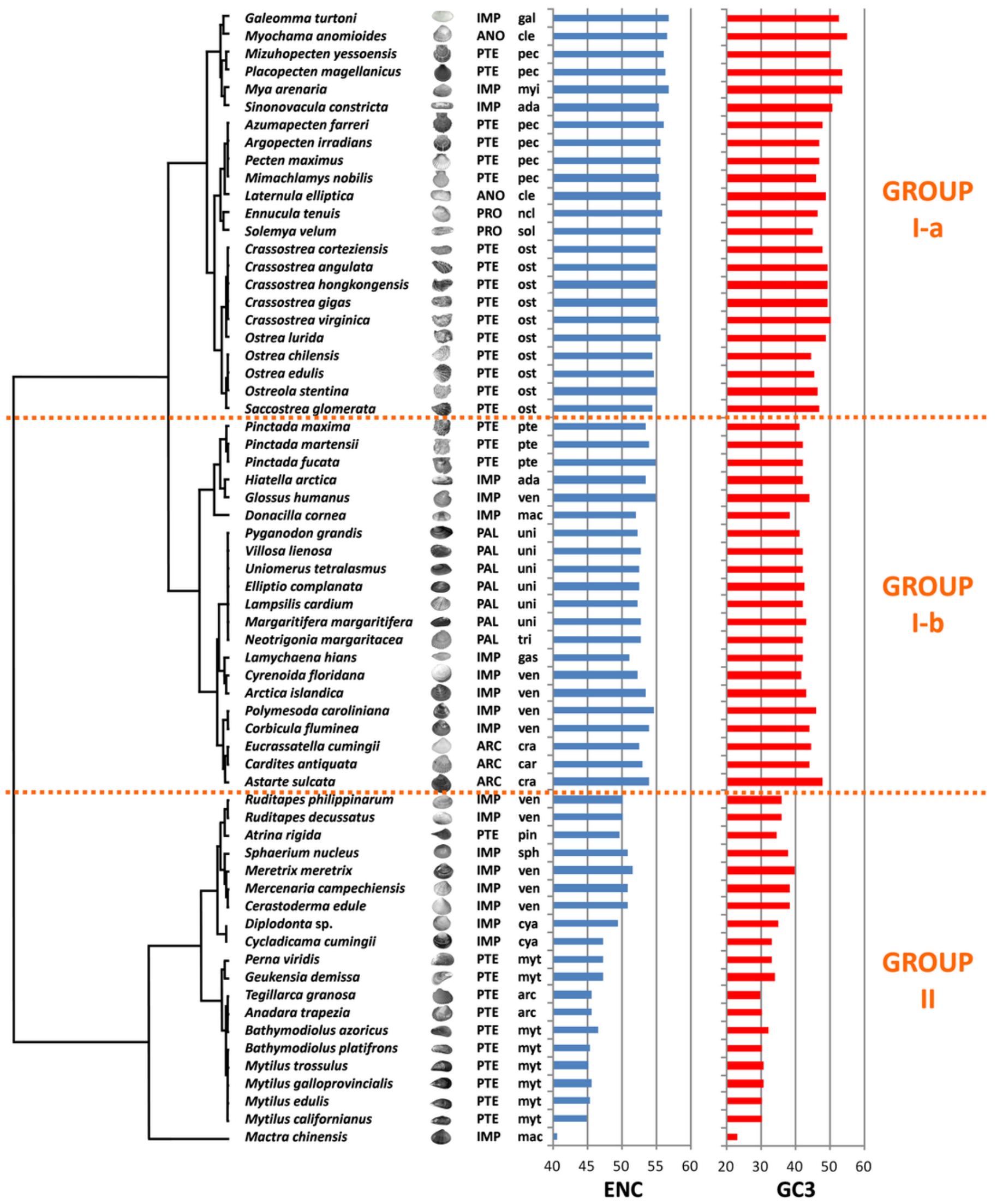




\section{3}

Codon usage bias in bivalves in mainly due to $A / T$-ending codons

Panel A: number of bivalve species (out of the 64 selected for this study) where a given codon was preferred (RSCU > 1). Panel B: Paerson correlation coefficient between the frequency of each codon and overall species CUB (negative ENC); NS = non-significant correlation, based on F-test of linear regression.

A.

\begin{tabular}{|c|c|c|c|c|}
\hline preferred & A & $\mathrm{T}$ & $\mathrm{C}$ & $\mathrm{G}$ \\
\hline \multirow{2}{*}{ AA } & 54 & 48 & 16 & 10 \\
\hline & Lys & Asn & Asn & Lys \\
\hline \multirow{2}{*}{ AT } & 28 & 58 & 19 & 1 \\
\hline & Ile & Ile & Ile & Met \\
\hline \multirow{2}{*}{$\mathrm{AC}$} & 64 & 25 & 9 & 0 \\
\hline & Thr & Thr & Thr & Thr \\
\hline \multirow{2}{*}{ AG } & 64 & 64 & 0 & 44 \\
\hline & Arg & Ser & Ser & Arg \\
\hline \multirow{2}{*}{$\mathrm{TA}$} & 1 & 39 & 25 & 1 \\
\hline & STOP & Tyr & Tyr & STOP \\
\hline \multirow{2}{*}{$\mathrm{TT}$} & 28 & 59 & 5 & 52 \\
\hline & Leu & Phe & Phe & Leu \\
\hline \multirow{2}{*}{$\mathrm{TC}$} & 64 & 60 & 17 & 0 \\
\hline & Ser & Ser & Ser & Ser \\
\hline \multirow{2}{*}{ TG } & 1 & 64 & 0 & / \\
\hline & STOP & Cys & Cys & Trp \\
\hline \multirow{2}{*}{ CA } & 4 & 54 & 10 & 60 \\
\hline & Gln & His & His & Gln \\
\hline \multirow{2}{*}{$\mathrm{CT}$} & 0 & 19 & 2 & 49 \\
\hline & Leu & Leu & Leu & Leu \\
\hline \multirow{2}{*}{$\mathrm{CC}$} & 64 & 57 & 7 & 0 \\
\hline & Pro & Pro & Pro & Pro \\
\hline \multirow{2}{*}{ CG } & 3 & 4 & 0 & 0 \\
\hline & Arg & Arg & Arg & Arg \\
\hline \multirow{2}{*}{ GA } & 49 & 60 & 4 & 14 \\
\hline & Glu & Asp & Asp & Glu \\
\hline \multirow{2}{*}{ GT } & 21 & 42 & 1 & 52 \\
\hline & Val & Val & Val & Val \\
\hline \multirow{2}{*}{$\mathrm{GC}$} & 63 & 64 & 35 & 0 \\
\hline & Ala & Ala & Ala & Ala \\
\hline \multirow{2}{*}{ GG } & 64 & 52 & 2 & 0 \\
\hline & Gly & Gly & Gly & Gly \\
\hline
\end{tabular}

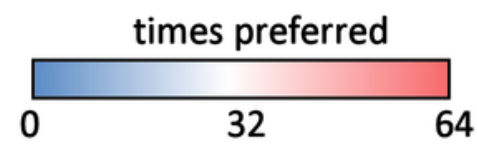

B.

\begin{tabular}{|c|c|c|c|c|}
\hline - ENC & $A$ & $\mathrm{~T}$ & C & $\mathrm{G}$ \\
\hline \multirow{2}{*}{$\mathrm{AA}$} & 0,86 & 0,9 & $-0,9$ & $-0,86$ \\
\hline & Lys & Asn & Asn & Lys \\
\hline \multirow{2}{*}{ AT } & 0,82 & 0,34 & $-0,92$ & 1 \\
\hline & Ile & Ile & Ile & Met \\
\hline \multirow{2}{*}{$A C$} & 0,84 & 0,71 & $-0,87$ & $-0,77$ \\
\hline & Thr & Thr & Thr & Thr \\
\hline \multirow{2}{*}{$A G$} & 0,95 & 0,9 & $-0,89$ & $-0,59$ \\
\hline & Arg & Ser & Ser & Arg \\
\hline \multirow{2}{*}{ TA } & / & 0,94 & $-0,94$ & I \\
\hline & STOP & Tyr & Tyr & STOP \\
\hline \multirow{2}{*}{ TT } & 0,93 & 0,91 & $-0,91$ & $0,24 \mathrm{NS}$ \\
\hline & Leu & Phe & Phe & Leu \\
\hline \multirow{2}{*}{$\mathrm{TC}$} & 0,91 & 0,84 & $-0,88$ & $-0,76$ \\
\hline & Ser & Ser & Ser & Ser \\
\hline \multirow{2}{*}{ TG } & / & 0,75 & $-0,75$ & 1 \\
\hline & STOP & Cys & Cys & Trp \\
\hline \multirow{2}{*}{ CA } & 0,85 & 0,91 & $-0,91$ & $-0,85$ \\
\hline & Gln & $\mathrm{His}$ & His & Gln \\
\hline \multirow{2}{*}{$\mathrm{CT}$} & $0,1 \mathrm{NS}$ & 0,2 NS & $-0,92$ & $-0,91$ \\
\hline & Leu & Leu & Leu & Leu \\
\hline \multirow{2}{*}{$\mathrm{CC}$} & 0,79 & 0,68 & $-0,87$ & $-0,73$ \\
\hline & Pro & Pro & Pro & Pro \\
\hline \multirow{2}{*}{ CG } & $-0,79$ & $-0,11 \mathrm{NS}$ & $-0,88$ & $-0,87$ \\
\hline & Arg & Arg & Arg & Arg \\
\hline \multirow{2}{*}{ GA } & 0,93 & 0,92 & $-0,92$ & $-0,93$ \\
\hline & Glu & Asp & Asp & Glu \\
\hline \multirow{2}{*}{ GT } & 0,85 & 0,9 & $-0,86$ & $-0,93$ \\
\hline & Val & Val & Val & Val \\
\hline \multirow{2}{*}{$\mathrm{GC}$} & 0,58 & 0,86 & $-0,89$ & $-0,78$ \\
\hline & Ala & Ala & Ala & Ala \\
\hline \multirow{2}{*}{ GG } & 0,54 & 0,75 & $-0,86$ & $-0,83$ \\
\hline & Gly & Gly & Gly & Gly \\
\hline
\end{tabular}

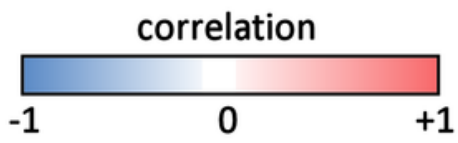


4

Simple linear regression analysis exemplifying the different contribution of four amino acids (Asn, Arg, Ser and His) to synonymous codon usage bias.

ENC values for each species are plotted on the $X$ axis and represent a measure of synonymous codon usage (lower ENC values indicate a stronger CUB). SENC-x values are plotted on the $Y$ axis and represent the relative intensity of CUB for each amino acid in each species. R squared correlation values are shown for each regression line. Detailed data for all amino acids are reported in Supplementary Table 5.

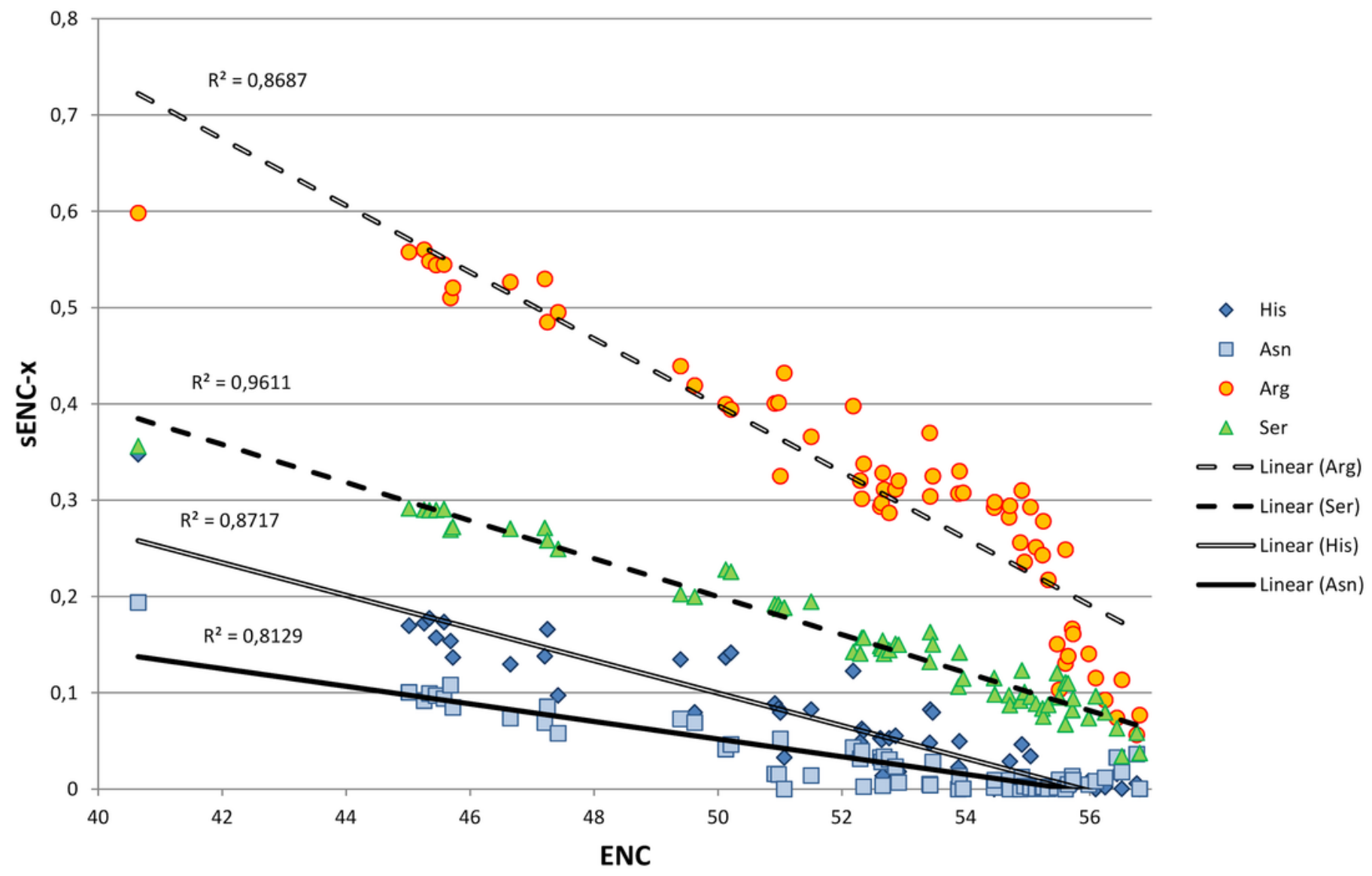


5

Regression line defining the correlation between $\mathrm{ENC}$ and $\mathrm{GC}_{3}$ in bivalve species

Species pertaining to the bivalve clustering group la, lb and II (see Figure 2) are marked as black, red and white circles, respectively. The P-value of the F-test of linear regression is $2.86 \times 10^{-36}$.

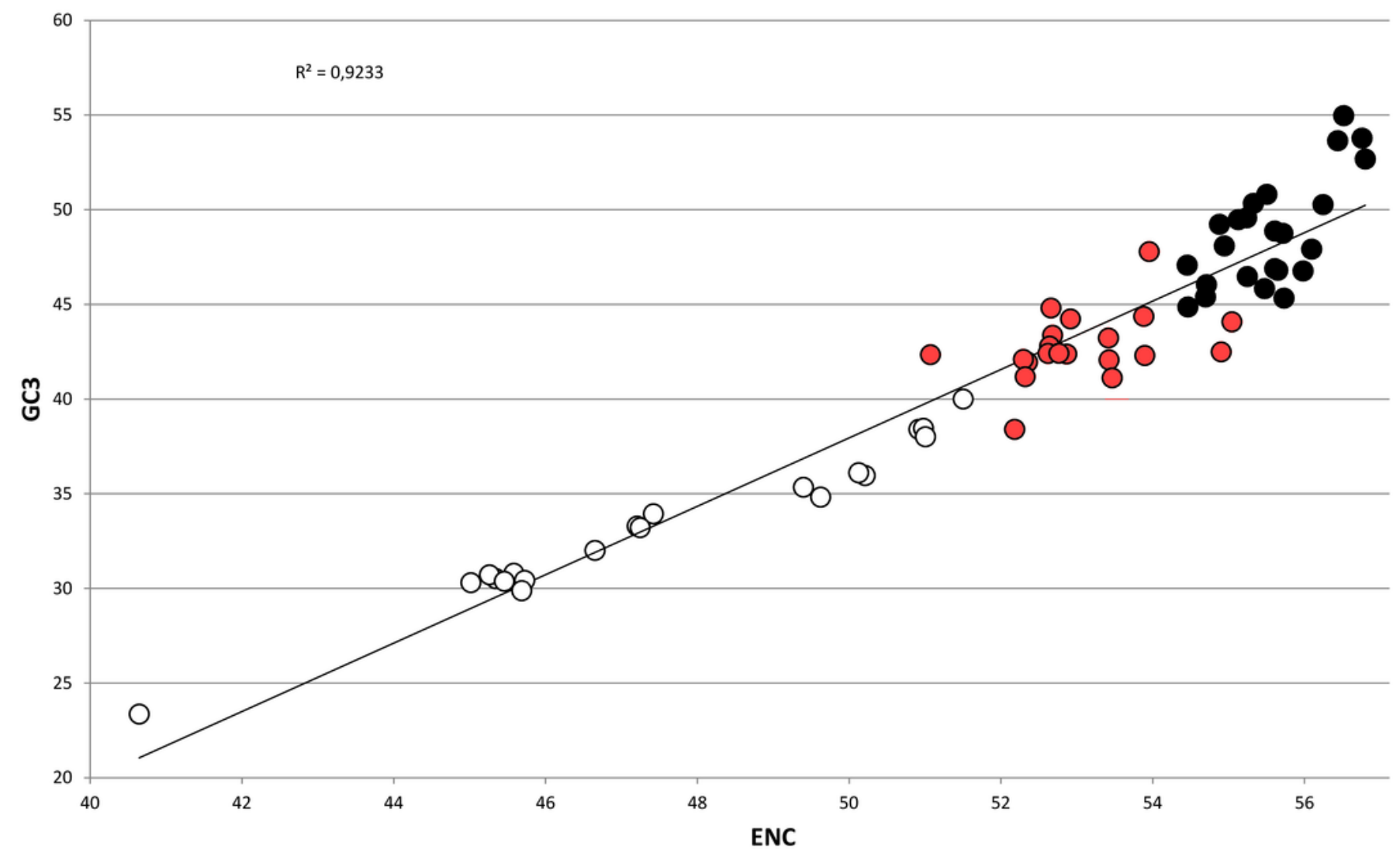




\section{6}

\section{CAI vs ENC plot}

Scatter plot of CAI (X axis) vs ENC (Y axis) for four representative bivalve species: Mactra chinensis, Mytilus californianus, Crassostrea gigas and Placopecten magellanicus. The reference set of highly expressed genes for each species is based on the orthologous genes of $C$. gigas (see Materials and methods).
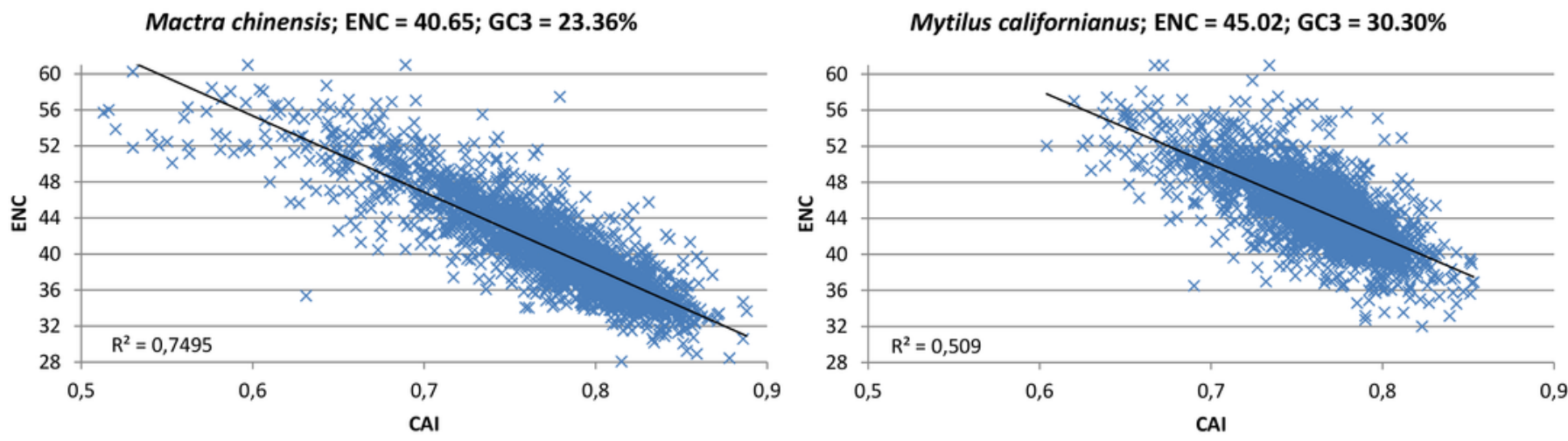

Crassostrea gigas; $\mathrm{ENC}=55.24 ; \mathrm{GC3}=49.47$

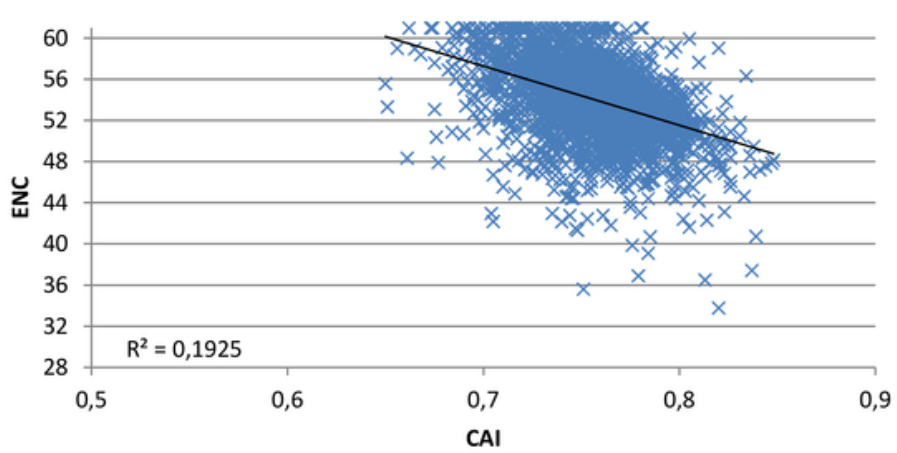

Placopecten magellanicus; ENC = 56.43; GC3 $=53.64 \%$

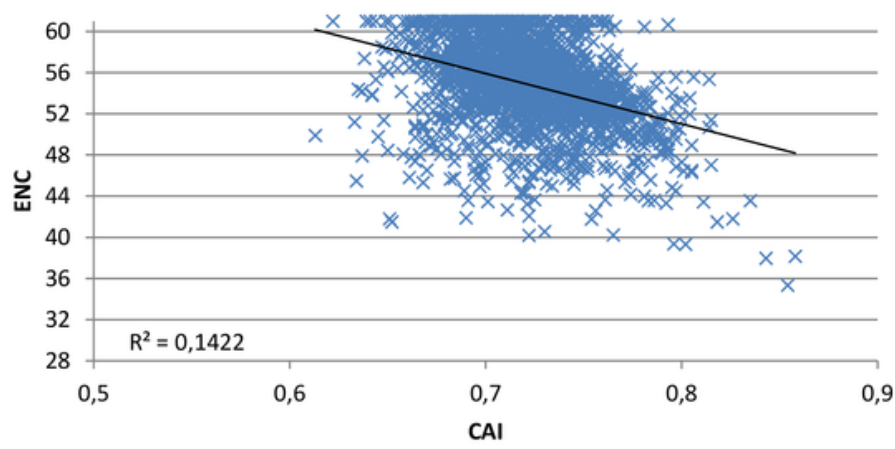




\section{Table $\mathbf{1}$ (on next page)}

Effective Number of Codons (ENC) in bivalves

Effective number of codons (ENC) values in bivalves, ordered from the least to the most biased species. * based on the revised classification of bivalves by Bieler et al. (2014). 
Species

Galeomma turtoni

Mya arenaria

Myochama anomioides

Placopecten magellanicus

Mizuhopecten yessoensis

Azumapecten farreri

Ennucula tenuis

Solemya velum

Laternula elliptica

Argopecten irradians

Ostrea lurida

Pecten maximus

Sinonovacula constricta

Mimachlamys nobilis

Crassostrea virginica

Ostreola stentina

Crassostrea gigas

Crassostrea angulata

Glossus humanus

Crassostrea corteziensis

Pinctada fucata

Crassostrea hongkongensis

Polymesoda caroliniana

Ostrea edulis

Ostrea chilensis

Saccostrea glomerata

Astarte sulcata

Pinctada martensi

Corbicula fluminea

Pinctada maxima

Hiatella arctica

Arctica islandica

Cardites antiquata

Neotrigonia margaritacea

Villosa lienosa

Margaritifera margatifera

Eucrassatella cumingii

Ellipto complanata

Uniomerus tetralasmus

Cyrenoida floridana

Pyganodon grandis

Lampsilis cardium
Taxonomic classification *

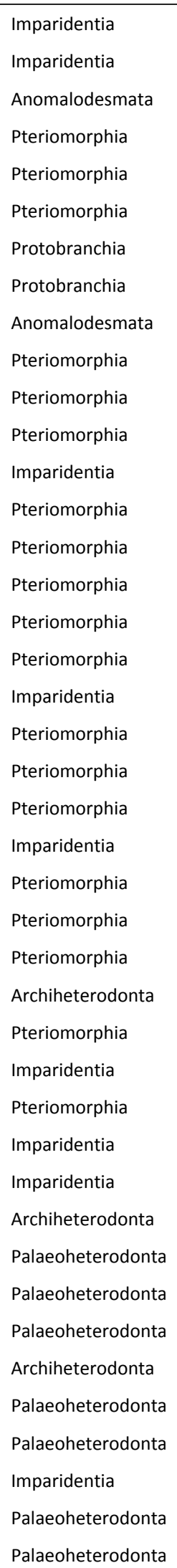

\section{Galeommatoidea}

Myidae

Cleidothaeridae

Pectinida

Pectinida

Pectinida

Nuculoidea

Solemyoidea

Cleidothaeridae

Pectinida

Ostreoidea

Pectinida

Adapedonta

Pectinida

Ostreoidea

Ostreoidea

Ostreoidea

Ostreoidea

Venerida

Ostreoidea

Pterioidea

Ostreoidea

Venerida

Ostreoidea

Ostreoidea

Ostreoidea

Crassatelloidea

Pterioidea

Venerida

Pterioidea

Adapedonta

Venerida

Carditoidea

Trigoniida

Unionida

Unionida

Crassatelloidea

Unionida

Unionida

Venerida

Unionida

Unionida
ENC

56.80

56.76

56.52

56.44

56.25

56.10

55.98

55.73

55.72

55.65

55.61

55.61

55.51

55.47

55.33

55.25

55.24

55.13

55.04

54.95

54.90

54.88

54.71

54.70

54.46

54.46

53.95

53.89

53.88

53.47

53.42

53.42

52.92

52.87

52.76

52.68

52.66

52.64

52.62

52.35

52.32

52.29 


Donacilla cornea
Meretrix meretrix
Lamychaena hians
Sphaerium nucleus
Mercenaria campechiensis
Cerastoderma edule
Ruditapes decussatus
Ruditapes philipinarum
Atrina rigida
Diplodonta sp.
Geukensia demissa
Cycladicama cumingii
Perna viridis
Bathymodiolus azoricus
Anadara trapezia
Tegillarca granosa
Mytilus galloprovincialis
Mythymodiolus platifrons
Mytilus trossulus
Machinensis
Malifornianus
Malis

Imparidentia
Imparidentia
Imparidentia
Imparidentia
Imparidentia
Imparidentia
Imparidentia
Imparidentia
Pteriomorphia
Imparidentia
Pteriomorphia
Imparidentia
Pteriomorphia
Pteriomorphia
Pteriomorphia
Pteriomorphia
Pteriomorphia
Pteriomorphia
Pteriomorphia

\begin{tabular}{|c|c|}
\hline Mactroidea & 52.18 \\
\hline Venerida & 51.50 \\
\hline Gastrochaenidae & 51.07 \\
\hline Sphaeriidae & 51.01 \\
\hline Venerida & 50.98 \\
\hline Venerida & 50.92 \\
\hline Venerida & 50.21 \\
\hline Venerida & 50.13 \\
\hline Pinnoidea & 49.62 \\
\hline Cyamiidae & 49.40 \\
\hline Mytilida & 47.42 \\
\hline Cyamiidae & 47.25 \\
\hline Mytilida & 47.21 \\
\hline Mytilida & 46.65 \\
\hline Arcida & 45.72 \\
\hline Arcida & 45.69 \\
\hline Mytilida & 45.58 \\
\hline Mytilida & 45.46 \\
\hline Mytilida & 45.34 \\
\hline Mytilida & 45.26 \\
\hline Mytilida & 45.02 \\
\hline Mactroidea & 40.6 \\
\hline
\end{tabular}




\section{Table 2 (on next page)}

Influence of mutational bias and selection on codon usage bias in Crassostrea gigas and Mytilus galloprovincialis

Paerson correlation coefficients and p-values of F-test for linear regression analysis are shown. 
Crassostrea gigas

\section{Coding $\mathrm{GC}_{3}$}

Global ENC

Genomic GC content

Mutational bias

Correlation between CUB and protein length

Correlation between $\mathrm{GC}_{3}$ and protein length

Selection for translational accuracy

Correlation between CUB and gene expression (hemocytes)

Correlation between $\mathrm{GC}_{3}$ and gene expression (hemocytes)

Correlation between CUB and gene expression (digestive gland)

Correlation between $\mathrm{GC}_{3}$ and gene expression (digestive gland)

Correlation between CUB and gene expression (gills)

Correlation between $\mathrm{GC}_{3}$ and gene expression (gills)

Selection for translational speed

Correlation between CUB and GC3

Prevailing factor at the whole protein-coding transcriptome scale

\section{$49.27 \%$}

55.24

$33.69 \%$

towards $\mathrm{A} / \mathrm{T}$-ending codons

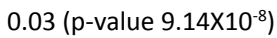

0.05 ( $p$-value 9.69X10-18)

towards G/C-ending codons

0.04 ( $p$-value $8.99 \times 10^{-12}$ )

0.03 ( $p$-value $1.44 \times 10^{-9}$ )

0.05 ( $p$-value $1.16 \times 10^{-17}$ )

0.06 ( $p$-value $1.04 \times 10^{-20}$ )

0.07 ( $p$-value $4.20 \times 10^{-29}$ )

0.06 ( $p$-value $6.14 \times 10^{-23}$ )

towards $\mathrm{G} / \mathrm{C}$-ending codons

-0.16 ( $p$-value $5.42 \times 10^{-148}$ )

mutational bias
Mytilus galloprovincialis

$30.80 \%$

45.58

$31.65 \%$

towards A/T-ending codons

0.09 ( $p$-value $3.75 \times 10^{-18}$ )

-0.10 (p-value $5.43 \times 10^{-22}$ )

towards $\mathrm{A} / \mathrm{T}$-ending codons

0 (NS)

0.07 (p-value 3.99X10-11)

0 (NS)

0.11 (p-value $2.67 \times 10^{-24}$ )

0 (NS)

$0.12\left(p\right.$-value $\left.1.04 \times 10^{-28}\right)$

towards G/C-ending codons

-0.53 (p-value 0)

Mutational bias and selection for translational accuracy 